\title{
A Technology Transfer Tracking System for NREI: Overview and Results
}

RECEIVED

AUG 211996

OSTI

R. L. Chapman, Ph.D.

M. J. Chapman, M.S.

Chapman Research Group, Inc.

Littleton, Colorado
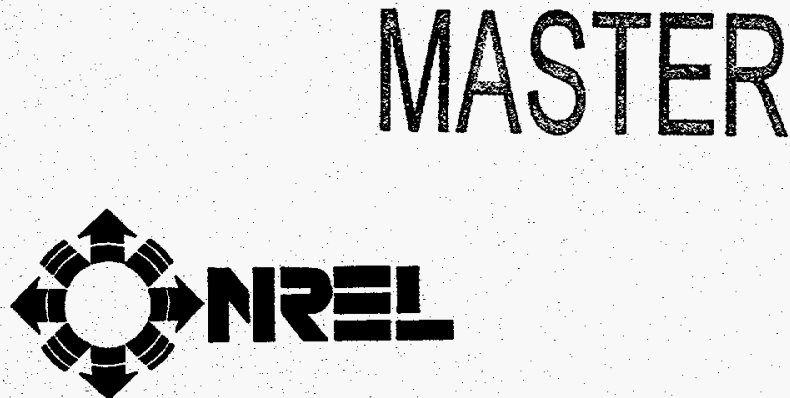

National Renewable Energy Laboratory 1617 Cole Boulevard Golden, Colorado 80401-3393

A national laboratory of the U.S. Department of Energy Managed by Midwest Research Institute for the U.S. Department of Energy under Contract No. DE-AC36-83CH10093 



\section{A Technology Transfer Tracking System for NREL: Overview and Results}

R. L. Chapman, Ph.D.

M. J. Chapman, M.S.

Chapman Research Group, Inc.

Littleton, Colorado

NREL technical monitor: Helena Harman

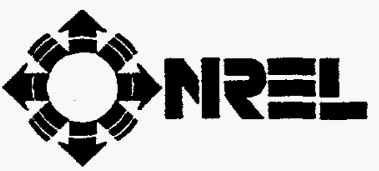

National Renewable Energy Laboratory 1617 Cole Boulevard Golden, Colorado 80401-3393

A national laboratory of the U.S. Department of Energy Managed by Midwest Research Institute for the U.S. Department of Energy under Contract No. DE-AC36-83CH10093

Prepared under Subcontract No. AAP-4-14322-01

July 1996 


\section{NOTICE}

This report was prepared as an account of work sponsored by an agency of the United States government. Neither the United States govemment nor any agency thereof, nor any of their employees, makes any warranty, express or implied, or assumes any legal liability or responsibility for the accuracy, completeness, or usefulness of any information, apparatus, product, or process disclosed, or represents that its use would not infringe privately owned rights. Reference herein to any specific commercial product, process, or service by trade name, trademark, manufacturer, or otherwise does not necessarily constitute or imply its endorsement, recommendation, or favoring by the United States govemment or any agency thereof. The views and opinions of authors expressed herein do not necessarily state or reflect those of the United States govemment or any agency thereof.

Available to DOE and DOE contractors from:

Office of Scientific and Technical Information (OSTI)

P.O. Box 62

Oak Ridge, TN 37831

Prices available by calling (423) 576-8401

Available to the public from:

National Technical Information Service (NTIS)

U.S. Department of Commerce

5285 Port Royal Road

Springfield, VA 22161

(703) $487-4650$ 


\section{DISCLAIMER}

Portions of this document may be illegible in electronic image products. Images are produced from the best available original document. 


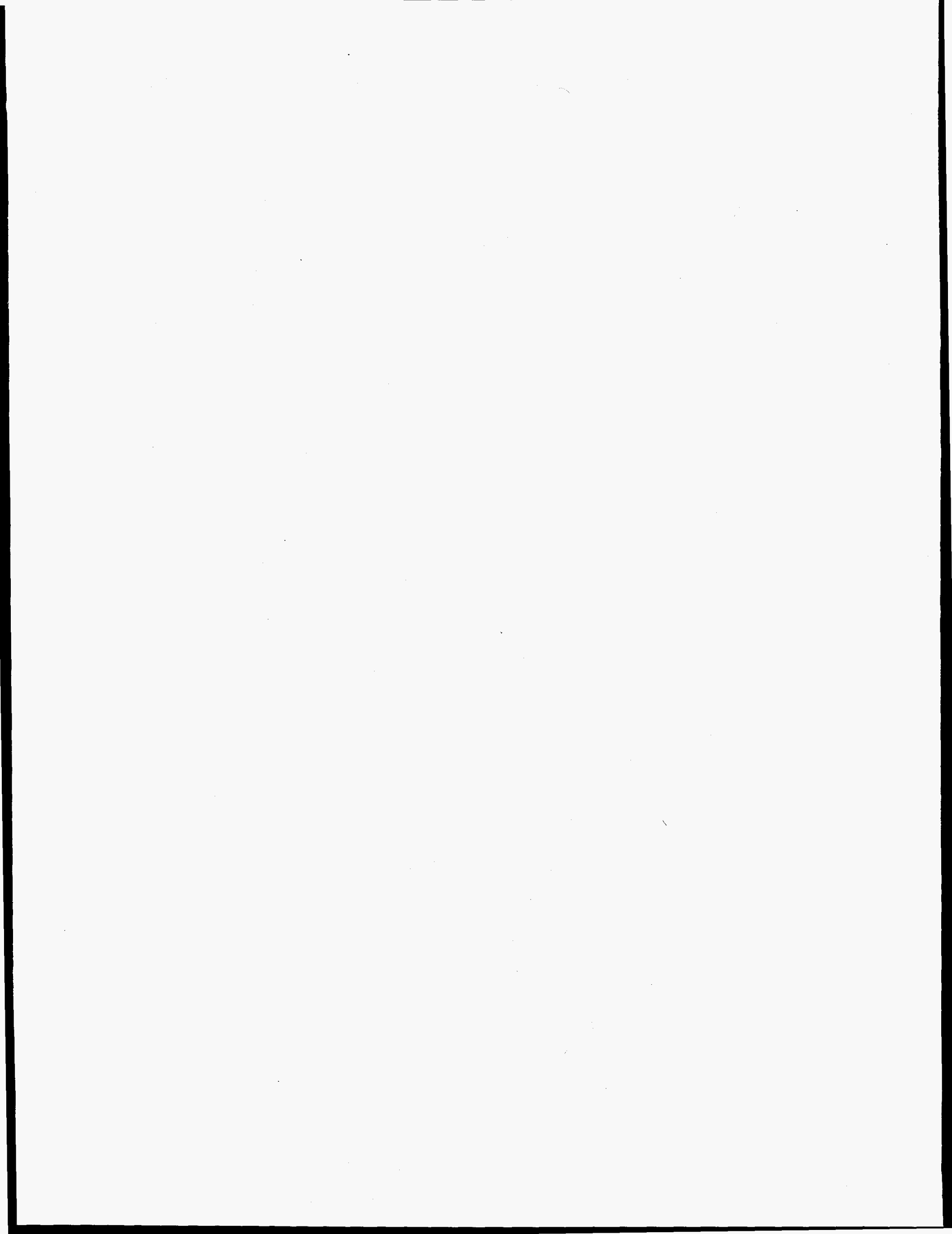




\title{
CHAPMAN RESEARCH GROUP, INC. 6129 South Elizabeth Way Littleton, Colorado 80121
}

\section{A Technology Transfer Tracking}

System for NREL: Overview and Results

\author{
by \\ Richard L. Chapman, Ph.D. \\ and \\ Marilyn J. Chapman, M.S.
}

\author{
March 1996 \\ Under NREL Subcontract No. AAP-4-14322-01
}

The material and views presented in this report are the sole responsibility of the authors and do not necessarily reflect the view of the National Renewable Energy Laboratory nor of NREL officials. 



\section{TABLE OF CONTENTS}

Acknowledgements

Page

ii

Foreword

iii

Executive Summary

iv

Background of the Project

1

The Pilot Study: Findings and Conclusions

3

A System for Tracking the Benefits of

NREL Research

A Practical Approach to Implementation

The Survey of NREL Technology Users

Observations and Conclusions

Annex 1. Methodology and Survey Instruments

Annex 2. Tables Aggregating Responses of Respondents Representing Formal Agreement Relationships and Technical Assistance 


\section{ACKNOWLEDGEMENTS}

The authors wish to express their thanks for the splendid cooperation and tolerance of NREL staff who helped through collection of documents, personal interviews and the provision of numerous information sources during the course of this study. Likewise, we are indebted to the 156 users of NREL technology who graciously contributed to our data collection via telephone interviews.

Special thanks are due to the staff of the Technology and Business Ventures Center, and especially to our contract monitor Dana Moran, ably assisted by Mary Pomeroy.

Richard L. Chapman, Ph.D.

Principal Investigator 


\section{FOREWORD}

The mission of the National Renewable Energy Laboratory, simply stated, is to develop new or improved renewable energy technologies and to assure their utilization on a timely basis. The process of conveying Laboratory research results to industry partners is referred to as "technology transfer." It is through technology transfer that the value of the national investment in NREL's research is realized. For that reason, from the beginning of the Laboratory in 1977, there has been a consistent emphasis on technology transfer.

Such transfer of technology to industry takes many different forms, both formal and informal. Some are active, such as patent licenses or subcontracts; others are passive, as in the publication of technical reports or the presentation of professional papers. Often the most effective modes are casual undocumented person-to-person exchanges.

While we have confidence that, over the last eighteen years, the Laboratory has successfully conveyed its advances to industry through these various channels, we felt a need to determine the effect of each mode of technology transfer, in order to place emphasis on the most viable techniques. In 1992, the NREL Technology Transfer Office engaged the Chapman Research Group, Inc. to undertake an in-depth analysis of the Laboratory's policies and practices for moving developments into commercialization. The five part study began with an assessment of research staff attitudes and habits in sharing new knowledge with the private sector, designed a system for tracking day-to-day transfer activities, and concluded with an assessment of the benefits of the Laboratory's technology transfer by conducting a comprehensive survey of NREL's industry partners. Detailed reports on each stage of the study have been issued. This, the final report, summarizes the conclusions and recommendations of the earlier phases, and details the results of the industry partner survey.

In addition to providing guidance for the management of the Laboratory's technology transfer initiatives, the CRG study has furnished objective assurance that the investment in renewable energy research at NREL is paying off, that industry is commercializing the advances in technology, and that society is benefiting thereby.

During the term of this study, the Chapman Research Group has served as an expert advisor to the Technology Transfer Office (now the Technology and Business Ventures Center) and has contributed to many of its initiatives. We want to thank Chapman Research and its principal, Dr. Richard Chapman, both for the successful conclusion of a wide-ranging and valuable analysis, and for invaluable advice and counsel.

Richard Marczewski, Director

Technology \& Business Ventures Center

National Renewable Energy Laboratory 


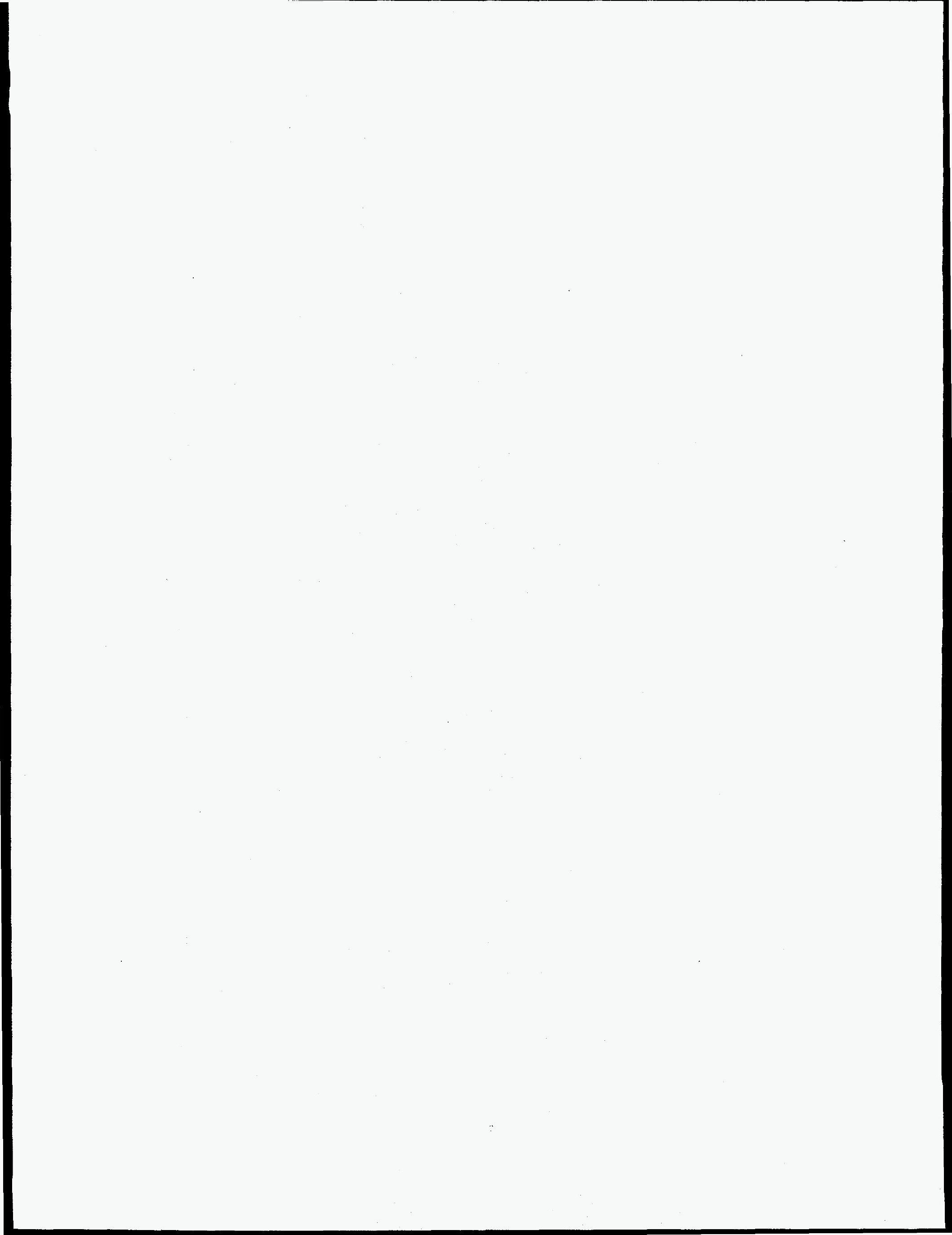




\section{EDITORIAL NOTE}

This study was completed in late 1995 . Shortly thereafter, major revisions were made in the Laboratory's organizational structure and management information systems. Those changes obviate many of the observations of Chapters 3 and 4 of this report, and render most of the recommendations in those chapters irrelevant to the current institutional framework. However, both in the interest of a complete summary of the study and because those recommendations may have relevance in another institutional setting, Chapters 3 and 4 have been retained in this final report. Additional details on those aspects of the study are available in the interim reports. 


\section{EXECUTIVE SUMMARY}

This report is an overview of a five-part study that has explored a means for tracking the benefits of NREL research, developed a system based upon the perceptions of users of that research, and concluded with a full-scale survey of such users.

The study demonstrates that NREL researchers strongly support the function of technology transfer leading to successful commercialization of NREL technology. Further, that they will be responsive to positive management actions toward facilitating such technology transfer activities. However, NREL researchers are most likely to be responsive as management demonstrates its commitment through providing the resources for successful technology transfer.

The study shows that a workable benefits-tracking system is practical, as outlined in some detail in Chapter 3, and tested as described in Chapter 4.

A full-scale survey of users of NREL technology provides a test of the kinds of information such a benefits-tracking system can provide. The survey involved 156 interviews with respondents representing organizations having had some kind of relationship, formal or informal, with NREL. Of these 106 had some kind of formal agreement (cost-shared subcontract, CRADA, license or Work for Others agreement), or received technical assistance. Among these, nearly three-fourths were able to estimate contributions toward sales or savings totalling more than $\$ 713$ million, while leveraging company investment of over \$104 million.

Respondents attested to numerous technical benefits, such as an increase in their companys' technical capabilities; access to equipment, tests or NREL researchers; and the avoidance of $\mathrm{R} \& \mathrm{D}$ "dead-ends." In addition, they cited intangible benefits such as an improved company image or credibility due to their NREL relationship, the improvement of morale in the company, and better contacts leading to expanded marketing.

As a whole, respondents in this group were satisfied in their relationship with NREL. They saw the greatest need for improvement (nearly half of those responding) in the negotiation and agreement execution process--especially the factor of timeliness. They also expressed the desirability for NREL becoming more sensitive to the needs of industry, especially the driving forces of cost and time.

The report concludes with a strong recommendation that NREL institute a systematic means for tracking the benefits of its research as part of its technology transfer/commercialization process in order to provide clear evidence of the value of its research program.

Richard L. Chapman, Ph.D. Principal Investigator 


\section{CHAPTER 1}

\section{Background of the Project}

The purpose of this study has been to assess the National Renewable Energy Laboratory's (NREL) technology transfer--both the activities and the system, with the objective of developing a system to track the benefits of NREL-sponsored or conducted research.

There were two factors which facilitated this study and which were important in the ability to make a detailed analysis and series of recommendations. First, was the narure of the lab, being one which, from its beginning, has worked closely with industry and, therefore, has been directed toward research which would be of value to industry and hopefully commercialized. Second, the size of the laboratory made it relatively more easy to address issues and to become familiar with the organization and with the scientists themselves.

In many respects NREL is not "typical" of most DOE contractor-operated laboratories. NREL was established nineteen years ago as the Solar Energy Research Institute with the purpose of conducting or supporting research designed to facilitate the practical commercialization of renewable energy technology. NREL is devoted to basic and applied research, less to product development. On the other hand, there are many differences among the other laboratories, and no single one can be considered "representative" of the total system. DOE labs vary from a few hundred researchers to thousands, some devoted almost exclusively to weapons programs, some in mostly basic research and others being multi-purpose and covering the whole domain of research, development and application. NREL does share several characteristics with other Department of Energy laboratories: first, it has a wide array of research and development activities involving a great many disciplines; second, it, like its sister laboratories, must work in a multi-tiered Department of Energy system which involves a certain amount of patience and fortitude; third, as a contractor-operated laboratory it has a certain degree of "independence" that is not usually found in government-operated laboratories. 
The study was undertaken in a series of five steps whereby each step built upon the preceding one, but could stand alone, permitting termination without sacrificing what had been learned. Those five steps were:

(1) A review of the existing technology transfer "system" and assessment of the "readiness" of the scientific staff;

(2) "Testing" possible results of seeking benefits data from users via a pilot survey;

(3) The development and screening of recommendations for a full-blown system;

(4) Conceptual testing the proposed system; and

(5) Conducting a full-scale survey of NREL technology users.

The first two of these steps were concluded in February 1993 and resulted in the report, "Developing a Technology Transfer Tracking and Identification Process for the National Renewable Energy Laboratory: Exploring and Defining Means." The third step resulted in the report, "A System for Tracking the Benefits of NREL Research," January 1994.

Step 4 did not immediately follow on the completion of Step 3. Conceptual testing of the system replaced the original plan to undertake an implementation test as time constraints precluded implementing management changes considered desirable to complete a total benefits tracking system. Step 4 concluded with the report, "Final Report: Technology Transfer Tracking System, Phase IV," August 1995.

Step 5 then became a full scale survey of NREL technology users to determine the capacity to obtain useful data across an array of technology transfer mechanisms-all of which have been employed extensively by NREL. This report concludes the study, summarizing the previous four steps, and focusses upon the full-scale survey. 


\section{CHAPTER 2}

\section{The Pilot Study: Findings and Conclusions}

The pilot study began in late summer 1992 and concluded with a report in March 1993. Its primary purpose was to determine whether or not a benefits tracking effort could be successfully instituted at NREL, and if the results could prove useful. This effort consisted of three parts: (1) a review of what constituted technology transfer at NREL in late 1992 and both the awareness of and attitudes toward the technology transfer function by NREL researchers; (2) a brief pilot survey of users of NREL technology; and (3) recommendations on how NREL might proceed.

\section{Perceptions About Technology Transfer at NREL}

In order ta better understand the "working level" perspective of technology transfer at NREL among its researchers, 25 representing all of the technical divisions were interviewed on a wide array of technology transfer processes, issues and concerns. Basically, these interviews revealed a strong positive climate for successful technology transfer at the research level. Subsequent interviews with each of the division directors revealed a similar set of perceptions.

\section{$\underline{\text { A Positive Climate for Technology Transfer }}$}

One of the first indicators of this "positive climate" was the extraordinarily strong awareness that technology transfer is an important job element at the bench level. Every researcher interviewed acknowledged that this was a key element of his or her job at NREL, and each could give examples of direct participation in a number of technology transfer activities. Most volunteered that a primary reason for their having come to work at NREL was their eagerness to see technology in the respective fields of NREL's responsibility come to fruition, be commercialized, and enjoy widespread use in the American economy. At least half of those interviewed were able to identify very specific sources of technology transfer information, and evidenced familiarity with them.

When questioned about the kind of emphasis placed on technology transfer in the management chain, most replied that they personally experienced considerable emphasis on this function from their immediate supervisors, and that this emphasis went up the management chain to the top laboratory management. 
However, and this is unusual among Federal laboratory scientists, these respondents indicated that the greatest emphasis came from their immediate supervisors. Further, each of the respondents gave a number of reasons as to why it was important for NREL to be successful in the technology transfer process, and, on the other side of the coin, were able to clearly identify the negative impact of a failure by NREL to effectively transfer its technology to societal use.

Finally, the NREL researchers were questioned about the kind of "pressure" they felt from NREL management for technology transfer--with particular emphasis on whether or not they perceived that there was either excess or too little pressure exerted. Fully two-thirds expressed that there was neither excess nor too little pressure exerted from top management to contribute to technology transfer processes. More than three-fourths of the respondents had been involved in at least monthly technical assistance activities, and all of the respondents had been involved in some technical assistance activities with organizations outside of NREL.

In summary, the survey revealed an excellent base of a positive climate for successful technology transfer at NREL, and a dedicated willingness on the part of NREL researchers to participate fully in this process.

\section{Institutional Barriers to Technology Transfer}

Recognizing that it has been only a few years since the top management levels in the Department of Energy have vigorously pressed technology transfer as a key activity for its laboratories, and that there has been a learning process concerning departmental guidance, there are some institutional barriers that can be addressed at NREL. Some of these clearly result from the nature of departmental guidance and policy.

Perhaps the most important is the belief among researchers that NREL management in the past has not been consistently supportive of technology transfer activities. Researchers perceive a contrast between what top management says and the action taken through providing supporting resources that would help researchers accomplish technology transfer. For example, technical assistance activities may have been truncated because researchers were precluded from providing more than brief assistance without having a project against which to charge such activity. 
This phenomenon was also seen where researchers had completed a project that involved a patent application process, but there were either limited or no funds available to carry the technology to the next step that might attract commercial attention. This same concern is reflected in the diversity among the divisions whereby the technology transfer representatives are given time to support this function. There was considerable disparity from one division to another in terms of the time permitted for the technology transfer representative to devote to this function.

Few of the researchers interviewed were able to describe awards that recognize technology transfer activities. The award system needs stronger support and promotion within the laboratory. However, the Department of Energy has been slow in developing a technology transfer award system Department-wide.

Another area which researchers believe deserves more attention is that of orientation, training, and providing information to researchers about the processes of technology transfer, the relative priorities given to different means within the laboratory, and information about successful transfers. Most believe that management attention needs to be given to the legal, patent, and procurement systems as they impinge on the technology transfer process. They believe that it is important for all levels of management within NREL to have a better understanding of the commercialization process and what is involved. Greater effort is needed to facilitate the commercialization process through better planning and the effective marshalling of resources.

Barriers to technology transfer across divisions, apparently have different effects depending upon the technology and the nature of the industry involved with that technology. For example, within the area of photovoltaics, there has been a real challenge to convince industry that the NREL scientists are not competitors with industry. However, the increased emphasis by the Department of Energy on protecting laboratory-initiated technology often makes it difficult for NREL researchers to separate what should be proprietary and what should be open in their cooperative work with industry. As NREL seeks to protect its intellectual property, it appears to limit both publishing and the more immediate cooperative activities with industry. Given the apparent vulnerability and insecurity of industry, researchers believe there needs to be clearer guidance on this issue.

Although these barriers are real and can inhibit the technology transfer process, one should be optimistic that they will be overcome as both the 
Department and Laboratory gain experience. This requires a strongly emphasized technology transfer function and the recognition that more resources should be allocated to it. The basic NREL culture is highly supportive of technology transfer.

\section{Results of the Pilot Survev of Users of NREL Technology}

In response to the $C R G$ request, 13 of the 25 NREL researchers interviewed furnished user leads for follow-up via telephone. It was recognized, in making this request, that about one-third of the NREL researchers interviewed were engaged in research which was at a stage that application or commercialization was judged too remote to follow up.

Those researchers who furnished user leads provided a total of 38 contacts. CRG completed interviews with 35 of these contacts. The other three were not available for the interviews or had not received permission to provide estimates of sales or savings data at the time that CRG closed out the data collection.

Each of the "user leads" was contacted by telephone (in some instances referred to other persons who were considered to be more knowledgeable about the inquiry). The interview instrument was divided into two parts: (1) a discussion relating to both tangible and intangible benefits derived from the use of the NREL technology, including estimates of sales or savings (to the extent that that could be obtained); and (2) perceptions of the respondent concerning the technology transfer process as it occurred between NREL and the organization.

\section{Benefits Deriving From the Technology Involving NREL as a Cooperator or Sponsor}

Three classes of benefits were evident from these interviews: (1) those benefits which could be quantified, if only on an estimated basis, (2) other tangible benefits, and (3) intangible benefits, With respect to quantifiable benefits, the emphasis was upon contributions toward sales; or savings in terms of labor, equipment, materials, testing or research and development costs; and an estimate of the company's investment in the technology application.

In 11 of the 36 applications followed up, the respondents were able to estimate sales related to the technology. Contributions to sales through the application of this technology were estimated to be between $\$ 14.4$ million and $\$ 15.4$ million. This did not include estimated potential future revenues between 
$\$ 4.2$ million and $\$ 5.2$ million per year. These figures include a mix of revenues that cover several vears in some instances to annual sales in other instances.

In terms of savings, 25 of the 35 respondents estimated savings in terms of research and development costs avoided, savings in labor, materials, testing and the like. The total savings estimates ranged from $\$ 11.6$ million to $\$ 12$ million.

Half, 18 of the 35 respondents, gave estimates of company investment. Total estimates of company investment ranged from \$22.8 million to $\$ 25.8$ million.

There were a number of comments concerning benefits that could be considered "tangible" yet for which the respondents were unable to give estimates. For example, over a third of the respondents noted the value of having worked with NREL which contributed to the credibility of results. A like number reported the value of avoiding "dead ends" in the research and development process. A similar number reported enhanced or extended technical capabilities because of the work with NREL. Others included access to equipment or access to technology. One acknowledged that NREL technology ". . . was the key to the company's success."

In the category of "intangible" benefits perhaps the one most often identified by more than half of the respondents was that of an improved or enhanced company image. A similar number acknowledged improved employee morale because of their affiliation with NREL. Several were more effusive: ". . .made the [company] team competitive," or ". . . gives company competitive edge over European and Japanese companies."

\section{Perceptions of the Technology Transfer Process}

There were six clusters of questions which reveal important perceptions of the technology transfer process as these organizations experienced them in their work with NREL. These include: (1) the nature of the initial contact; (2) the kind of response on the part of NREL; (3) their experience with NREL's sharing information; (4) the effectiveness of the technology transfer mechanism used in the cooperative work with NREL; (5) whether or not they would pursue an effort with NREL in the future; and (6) other comments.

Regarding the initial nature of the contact, 69 percent of the respondents clustered into three means: (1) through answering a request for proposal (RFP); (2) through a professional meeting; and (3) via previous work such as under 
contract with SERI or NREL, or through a former employee of SERI/NREL. Forty percent reported that their initial contact was either through previous work or through a Request for Proposal. However, 35 percent of those interviewed indicated that the first contact was through a professional or trade association meeting, and several even indicated that the first contact was "over cocktails" at such a meeting.

On the question of NREL response, 94 percent of the respondents indicated that it was not difficult to identify the persons with whom they should speak at NREL, and that their subsequent contacts provided quick response in return to their initial inquiries.

Eighty-three percent of the respondents also had favorable comments on NREL's practice of sharing technical information with their cooperators. Most indicated that they received information on a timely basis and that they had no problem with the willingness of NREL researchers to share information. On the other hand, several were concerned about what they perceived to be an increasing "wariness" on the part of NREL in sharing technical information. Several attributed this to the Department of Energy's desire to "protect" intellectual property developed within the laboratories. One respondent was unhappy about a failure to reach agreement with NREL representatives on a license.

Most respondents had experience with either a subcontract or a CRADA. With rare exception they found these quite satisfactory and praised them as effective tools of technology transfer. Slightly less than one-fourth of the respondents were involved only in informal agreements, which they praised highly.

All of the respondents indicated a willingness to work with NREL on future projects. They tended to view NREL as an excellent source of technology, and as an organization with which they liked to work.

There were three other comments that stood out. Many praised NREL researchers as "dedicated and helpful." Others praised the NREL technology available and what they perceived to be a productive relationship with NREL researchers. Finally, respondents valued cooperative work with NREL for giving a special boost to U. S. industry. They perceived NREL researchers as being sensitive to industry needs and willing to work on those needs. 
The most common mechanisms for technology transfer revealed in the pilot survey were:

- Thirty-seven percent were by shared-cost subcontract.

o Twenty percent were through technical assistance.

o Seventeen percent were by CRADA/formal agreement.

o Fourteen percent were by informal collaboration.

\section{NREL Should Develop a Technology Benefits Tracking System}

NREL should give serious consideration to developing an internal system that would cover the 13 means of technology transfer that NREL has used currently and in the past. These include:

- Cooperative Research and Development Agreements

- Licenses

o Work for Others Agreements

- Facilities Use Agreements

- Subcontracts

- Spinoff Companies

o Publications

o NREL-sponsored Conferences and Workshops

o Researcher Exchanges

- Education and Training

- Professional or Trade Association Meetings

- Technical Assistance

- Informal Collaborations

Clearly such a system cannot be instituted all at one time. It is important that NREL officials review the various suggestions for how identification and tracking might be undertaken in each of the 13 means and prioritize those which seem to be most easily accomplished, as well as those which are most important for collecting the information considered essential. A strategy for implementation can then be developed and put into place over time.

NREL has undertaken a program of internal orientation for NREL employees directed toward both managers and researchers. They need to be sensitized to the 
importance of capturing this kind of information as a means of sustaining successful technology transfer in support of NREL's various programs. Such an orientation program is at least as important as general DOE efforts to encourage industry to come to its laboratories for assistance.

NREL officials need to implement a system for following up and obtaining data from NREL research "users." NREL ought to examine the extent to which assistance might be available from the Analytical Studies Division 


\section{Chapter 3}

\section{A System for Tracking the Benefits of NREL Research}

The third step in this project was directed toward developing a detailed description of an "ideal" benefits tracking system for NREL. The pilot study demonstrated that NREL researchers basically were quite receptive to full participation in the technology transfer function. This provided the essential foundation upon which a benefits tracking system could be built if the system could be folded into the normal NREL reporting and accountability process. Therefore, the tracking system would need to be integrated with ongoing NREL policy, combined with appropriate orientation.

It was recognized that the full array of technology transfer mechanisms should not be incorporated into the system at the outset, but included over time so as to permit easier transition and acceptance. Further, successful examples of transfer should be well publicized to encourage reporting, supplemented by a wellpublicized means for recognition of "good work" in the transfer of technology.

Finally, the tracking system should make full use of current data collection and reporting to avoid duplication and frustration among researchers.

\section{Elements of a Tracking System}

A complete, effective benefits tracking system needs to cover the various mechanisms for technology transfer and include the three functions essential to the system:

1. identifying opportunities for transfer;

2. initial recording of transfer activity; and

3. tracking and evaluation of transfer information.

The assignments were made with the recognition that both the Technology and Business Ventures Office and the Division Technology Transfer Representatives will require supplementation of resources and/or allocation of more professional time.* There is no reason why the system cannot be approached in an incremental

*The Technology Transfer Office became the Technology and Business Ventures Office in 1995, and the Technology and Business Ventures Center in February 1996. 
fashion, undertaking those responsibilities that will produce the most essential data initially, then phasing in other responsibilities as experience is gained. It would be wise to begin with capturing data on subcontracts, Work for Others, licensing, CRADAs and facilities use before tackling technical assistance and informal collaborations among scientists.

\section{Group I: Relatively Easy to Track}

\section{Cooperative Research and Development Agreements (CRADAs)}

Have a reporting requirement of CRADA partners similar to that for a Contracting Officer's Technical Representative reporting on subcontracts.

\section{Responsibilities}

a. Technology and Business Ventures Office (TBVO)

(1) maintain central data file on CRADA status, progress, and transfer activity.

(2) retain and exercise $T^{2}$ management responsibility; monitor and assist PIs and Division $\mathrm{T}^{2}$ Reps in evaluating for $T^{2}$ opportunities.

(3) maintain a "tickler" file for periodic follow-up at some period (determined with the assistance of the PI) after completion of the CRADA.

b. Principal Investigator (PI)

(1) identify opportunities for transfer.

(2) initial recording of transfer activity.

c. Division Tech Transfer Representatives

(1) check PIs quarterly for transfer activity.

\section{Licensing}

\section{$\underline{\text { Responsibilities }}$}

a. Technology and Business Ventures Office

(1) identify opportunities for transfer

[This requires close collaboration with the PI; also possibly some new activity related to marketing the technology]. 
(2) initial recording of transfer activity.

(3) tracking and evaluation of data.

(4) periodically check Division $T^{2}$ Reps and patent holders for opportunities/activity--i.e. will something else grow out of the patent? Can it be applied to some other use? (For example, thin walled insulation can be used for hot as well as cold applications).

Applicable data should include license fees and royalty payments; nature of (and limits to) applications; sales or savings resulting from applications; user investment (if available); perhaps some "management" information such as perceived competition or infringement.

\section{Subcontracts}

Potential technology transfer "activities" that should be reported from a subcontract:

o new technology reported, e.g. to NREL (this should include all new technology, not just that which is considered patentable);

o technology made available to others:

- via licensing

- via collaboration (formal agreement or informally)

- information or researcher exchanges

- written documentation (papers, articles, reports)

- via presentations, symposia, workshops, demonstrations

NOTE: A checklist should be developed following the various categories above. Apart from checking the kind of activity(category), the form should include:

o recipient of the technology (by the PI)

o how the technology was used (if known first-hand by PI, or TBVO; otherwise by follow-up)

o results of the use: quantitative and qualitative (e.g. sales, savings, investment, non-monitory benefits) 


\section{Responsibilities}

a. Contract Officer's Technical Representative (COTR) (This probably is also the NREL PI)

(1) identify opportunities for transfer.

(2) initial recording of transfer activity, e.g. reports of new technology and technology made available to others.

b. Division Tech Transfer Representative

(1) check COTRs periodically for tech transfer activity.

(2) monitor close out, check with PI at that time.

(3) pass information to TBVO.

c. Subcontract Administrator

(1) monitor close-out for tech transfer activity; notify Division Tech Transfer Rep of impending close-out.

d. Technology and Business Ventures Office (TBVO)

(1) maintain a central file of tech transfer activities from subcontracts.

(2) retain and exercise tech transfer management responsibility.

(3) arrange for or undertake follow-up to determine results of technology transfer.

\section{Work for Others}

Report the same "activities" as is done for subcontracts, to include a brief description of and the nature of the data developed--i.e. is it patented, proprietary, limited distribution or open?

\section{Responsibilities}

a. Technology and Business Ventures Office

(1) maintain master list of WFO agreements (with $\mathrm{T}^{2}$ data).

(2) retain and exercise $T^{2}$ management responsibility.

(3) periodically check Division $\mathrm{T}^{2}$ Reps for WFO transfer activity. 
b. Principal Investigator (PI) [These functions may be delegated to a specific person on the team.]

(1) identify opportunities for transfer.

(2) initial recording of transfer activity

(3) complete a closeout report to TBVO at conclusion of the project, summarize transfer activities, with specific contacts.

c. Division Tech Transfer Representatives

(1) check PIs periodically for transfer activity.

\section{Use of Facilities}

\section{Responsibilities}

a. Branch Head or Division Director

(i.e., person responsible for the facility; this reporting may be delegated to the person who oversees the specific use)

(1) record any transfer activity growing out of facility use.

(2) identify transfer opportunities growing out of facility use.

(3) complete a close out report, summarizing transfer activities, with specific contacts.

b. Division Tech Transfer Representative

(1) collect and forward to TBVO transfer activity associated with use of NREL facilities.

c. Technology Business Ventures Office

(1) maintain central file of transfer activity associated with facility use.

(2) monitor and assist Division $T^{2}$ Reps in tracking/evaluating this transfer activity.

\section{Publications}

\section{Responsibilities}

a. Division Communications Coordinator (ComCord)

(1) provide to Division $T^{2}$ Rep a monthly report of publications in process or final stages. Include information e.g. principal authors, affiliation, prospective audience. 
b. Division Tech Transfer Representatives

(1) in conjunction with Division Communications Coordinators or NREL authors, determine potential spinoff activity.

(2) monitor distribution for possible follow-up.

(3) report publication activity quarterly to Technology and Business Ventures Office.

c. Technology and Business Ventures Office

(1) monitor Division $\mathrm{T}^{2}$ Rep reports on publications for potential transfer activity.

(2) in consultation with Division $\mathrm{T}^{2}$ Reps determine desirability of follow-up activity.

\section{NREL-Sponsored Conferences, Workshops and Program Reviews}

\section{Responsibilities}

a. Technology and Business Ventures Office

(1) maintain a central file of NREL presentations and workshops, including NREL participants and attendees.

(2) coordinate with Division $T^{2}$ Reps on possible follow-up with attendees, as well as means to collect information about these activities.

(3) conduct follow-up, or arrange through a third party.

b. Division Tech Transfer Representatives

(1) in cooperation with the TBVO, collect information about NREL sponsorship or participation in presentations and workshops including NREL participants, other attendees, nature of the technology, transfer activities/opportunities and the like.

\section{Spin-off Companies/Spin-off Emplovees}

\section{Responsibilities}

a. Technology and Business Ventures Office

(1) consult with Division $\mathrm{T}^{2}$ Reps for effective means to capture this information.

(2) periodically check with Division $T^{2}$ Reps for instances of transfer through the spin-off of companies or employees from NREL. 
(3) follow-up with contacts at appropriate interval.

\section{Group II: Relatively Difficult to Track}

\section{Technical Assistance}

\section{Responsibilities}

a. NREL Researchers

(1) record in lab notebook or on PC transfer activity e.g. telephone inquiries, visits, letters or FAX requesting assistance or technical information. Include name of contact, organization and address or telephone number for possible follow-up.

(2) make this information available to the Division $\mathrm{T}^{2}$ Rep on a monthly basis. (May wish to include this in a monthly activity report.)

b. Division Tech Transfer Representative

(1) collect this information from Division researchers on a regular, monthly basis. Review for desirability of follow-up, and identify good candidates for follow-ups.*

(2) consolidate information and any recommendations and send to TBVO.

c. Technical Inquiry Service

(1) screen records of all requests monthly to eliminate "off the street" or lay requests.

(2) forward to TBVO remaining requests and their disposition--to include nature of request, name of requestor, requestor's organization, address and telephone number. Identify NREL or other person if a referral was made.

*Follow-up by TBVO would be made at a time determined to be best in terms of "something has resulted," e.g. an application, commercialization, etc. If considerable time is likely to elapse before some significant result, a follow-up can be made to determine status and stay in touch with a knowledgeable person. Where action has occurred, obtain a description and results (or potential results) including specific benefits. 
d. Technology and Business Ventures Office

(1) maintain central file of technical assistance

(2) with Division $T^{2}$ Reps determine basis for follow-up*

(3) conduct periodic follow-up.*

\section{Informal Collaborations}

\section{Responsibilities}

a. NREL Researchers

(1) record in lab notebook or on PC nature and results of informal collaborations that result in transfer into or out of NREL. Include name of collaborator/contact, organization and address and telephone number for possible follow-up.

(2) make this information available to the Division $T^{2}$ Rep on an annual basis.

b. Division Tech Transfer Representative

(1) collect this information from Division researchers on an annual basis. Review for possible follow-up.

(2) consolidate information along with recommendations to the TBVO.

c. Technology and Business Ventures Office

(1) maintain central file of transfer activity via informal collaborations.

(2) determine basis for follow-up in consultation with Division $\mathrm{T}^{2}$ Reps.

\section{Education and Training}

\section{Responsibilities}

a. Technology and Business Ventures Office

*Follow-up by TBVO would be made at a time determined to be best in terms of

"something has resulted," e.g. an application, commercialization, etc. If considerable time is likely to elapse before some significant result, a follow-up can be made to determine status and stay in touch with a knowledgeable person. Where action has occurred, obtain a description and results (or potential results) including specific benefits. 
(1) maintain a central file of technology transfer activities resulting from training and education functions, whether formal or informal.

(2) coordinate with Division Tech Transfer Representatives on means to obtain brief descriptions of training and education activities and the persons involved.

(3) periodically followup with individuals involved to determine tech transfer results.

b. Education Office

(1) identify precollege $(K-12)$ and both undergraduate and graduate education programs that are considered to have specific instances of technology transfer activity.

(2) coordinate with the TBVO for appropriate means to follow up on possible technology transfer activities.

c. Division Tech Transfer Representatives

(1) Annually collect from Division researchers brief descriptions of education and training activities likely to have had technology transfer results and the names and points of contact of those involved.

\section{d. NREL Researchers}

(1) record instances in which the researcher is involved in an education or training activity that was likely to have technology transfer benefits. This record should include a brief description of the activity, the persons involved, and how they can be contacted.

\section{Researcher Exchanges}

\section{$\underline{\text { Responsibilities }}$}

a. Human Resources Office

(1) maintain records on researcher exchanges

(2) semi-annually forward to the TBVO a summary of such exchanges to include the external organization involved, the NREL Division and Branch involved, the individual involved and the nature of the work undertaken by the researcher. 
b. Branch Heads

(1) record instances of researcher exchanges: nature of exchange, persons involved, how they may be contacted, results achieved.

(2) forward this information to the TBVO via Division $T^{2}$ Reps semiannually.

c. Technology and Business Ventures Office

(1) maintain central file on transfer activity associated with researcher exchanges.

(2) collaborate with Division $T^{2}$ Reps and Human Resources Office to assure full collection of instances.

(3) determine desired follow-up procedure.

\section{Professional, Trade Association and Similar Meetings}

\section{Responsibilities}

a. Division Tech Transfer Representative

(1) maintain record of such meetings and Division researchers who attend including dates, purpose, papers presented, contacts made and any follow-up by researchers or others in NREL referred to by attendees.

(2) provide information to TBVO on a quarterly basis

b. Technology and Business Ventures Office

(1) maintain central file on meeting activities, papers, exhibits, contacts and results, coordinating with the Management Information Systems and Communications Office (MISCO).

(2) in consultation with MISCO and Division $\mathrm{T}^{2}$ Reps determine desirability/feasibility to follow-up.

\section{Determining Benefits}

Up to this point nothing has been discussed concerning the process for determining benefits. Attention has been directed to identifying technology transfer activities, then obtaining sufficient (but limited) documentation to permit follow-up. This emphasis on identification and documentation is made because experience shows that this is the essential, but often neglected step in trying to unearth 
information about benefits. Without knowledge that a transfer occurred (or possibly occurred) and some point of contact with the user, systematic data collection is virtually impossible.

\section{Collecting User Benefits Data}

The Technology and Business Ventures Office should be NREL's primary location for coordinating, archiving and assessing benefits data. The TBVO also will actually do considerable collecting of information via already existing means of reporting, and through the division Technology Transfer Representatives. By the very process of technology transfer, some benefits information will be acquired by researchers, branch heads, etc. that can be passed to the TBVO via the division Technology Transfer Representatives.

The process of follow-up with users presents a challenge since this is a demanding, time consuming and sensitive task. Conceivably, this could be done by the TBVO staff. However, experience strongly suggests that this can most efficiently and effectively be accomplished by a third party not institutionally connected with the Laboratory.

Any system of data collection faces trade-offs between cost and effectiveness. Ideally, one would like to have hard data on the exclusive impact the application of a particular technology has for the user--perhaps beyond that, on the national economy. Unfortunately, this objective can only be met by extensive data from the user which is a costly process. Most private businesses shun such intrusion as costly in their time with the possibility that it can lead to unacceptable disclosure of proprietary business information. This approach is best reserved for detailed case studies.

Experience shows that relatively brief, but structured telephone interviews with users is successful in eliciting their estimates of benefits. Usually one can obtain such estimates concerning sales, savings in time, materials, maintenance and $R \& D$, or cost avoidance. Although these estimates constitute "soft" data, it does represent best estimates by the user. In addition, such interviews provide the user the opportunity for candid assessment of the technology transfer process, its strengths and weaknesses.

Sales and savings data from a particular user should be protected as proprietary information, and used publically only in aggregation with dara from 
others or with the explicit consent of the organization or person who provided the data.

Where a particular technology transfer mechanism, such as technical assistance, may produce hundreds of possible transfers annually, the Laboratory management may choose to undertake a sample of these rather than undertake follow-up on the whole lot.

One always wishes to maintain a cordial relationship with the technology user. This generates support for the Laboratory and encourages future cooperative activities. Thus, follow-up contact with a particular person or organization should not be undertaken more frequently than annually, unless invited to do so by the user.

In summary, the collection of benefits data should be guided by the following principles:

- Make full use of current reporting practices.

- Avoid duplicative or unnecessary reporting by Laboratory researchers.

- Provide incentives for reporting by researchers.

- Use a third party to conduct follow-up with users.

- Use telephone interviews for follow-up.

- Protect users' proprietary information.

- Be judicious in making repeat follow-ups. 


\section{Implementing the Svstem: An Ideal Approach}

There are four key elements that require integration as part of implementing the proposed system for identifying, tracking and determining benefits from NREL research. These are: (1) the development and emplacement of supporting technology transfer policy needed to provide the basis for the system, (2) orientation of NREL staff, (3) publicizing technology transfer successes, and (4) putting in place the actual data collection system.

\section{Technology Transfer Policy}

This or any system of follow-up to determine benefits of NREL research requires institutionalized support for both the Technology and Business Ventures Office and the division Technology Transfer Representatives since both groups will have additional responsibility, and will require additional time. This requires specific enumeration of duties in addition to those already in place for these two groups.

The Division Technology Transfer Representatives will need to devote more time to both the old and new responsibilities. There is considerable difference among the various divisions in terms of the time allocated to this representation function. In some instances it includes the careful scrutiny of on-going technology transfer activities and communicating them--both within the division and to the DOE program levels. In other instances it may involve primarily periodic meetings with other Technology Transfer Representatives. Senior management should establish minimum standards and resource allocation for this function within each division.

As part of this policy, NREL should establish an internal award system directed toward recognizing excellence in technology transfer. This should be in addition to seeking awards of the Federal Laboratory Consortium and the R\&D 100 program.

\section{Orientation of NREL Staff}

Several years ago a handbook was distributed to all employees titled, NREL. Technology Transfer and You: A Guide to Technology Transfer at the National Renewable Energy Lab. This is an excellent piece, but it should be supplemented by specific orientation, beginning with the top Lab management and including all employees. 
There should be an orientation of senior managers to include all branch heads and division directors giving them details on the proposed system for identification, tracking and determination of NREL research benefits. The proposed program will have to be "sold" to senior management initially, and then an orientation given in some detail at the division and branch levels to assure both understanding and support. This should be followed by an orientation of all research staff, because ultimately, the individual researchers will be called upon to provide key inputs to the system-especially those involving technical assistance, informal collaboration, and other "hard to discover" technology transfer activities. Finally, there should be an element in the new employee orientation program to include a general overview of technology transfer, its purpose and value.

As the full program (Phase I and Phase II) is implemented, orientations can be given just prior to implementation. For example, the Phase I implementation involves data collection on the more formal technology transfer mechanisms: CRADAs, licensing, subcontracts, Work for Others, facilities use, publications, NREL-sponsored conferences, workshops and program reviews, and spinoff companies/spinoff employees. Those most involved in making contributions to this process will be the Technology and Business Ventures Office, the division Technology Transfer Representatives, the division communication coordinators, representatives from procurement, the Education Office, the Human Resources Office, division directors and branch heads. Prior to the implementation of Phase II which involves data collection on the more difficult mechanisms (technology assistance, informal collaborations, education and training, researcher exchanges, and professional trade associations/similar meetings) the audience should include all researchers, particularly the Principal Investigators and Project Leaders to help them understand both the need for and the value of their contribution to this effort. It will be important to provide some excellent case examples in these orientations-especially those to the researchers--in order that they can have an appreciation for the value of this information to NREL, especially to their respective laboratory sections, and to the Department and the nation at large.

\section{Publicize Technology Transfer Successes}

The TBVO should continue to collect case examples of technology transfer successes for the orientation process, but also for outreach activities. At a minimum, such examples should continue to be published in issues of the NREL In Review as a highlight feature, and in other appropriate NREL publications. 
In addition, there should be technology transfer awards. This needs to be done to make employees aware of opportunities for recognition through this award system, and to further demonstrate management's support of this function.

\section{Data Collection}

Data collection efforts--the initial identification and tracking process and the follow-up to obtain benefits data should be coordinated by the Technology and Business Ventures Office, and that office should be the principal repository for this type of data.

During the initial stage, data should be collected from regular reports such as the monthly and quarterly status reports from the various technical divisions, periodic reports on CRADAs, licenses, subcontracts, Work for Others, facilities use, researcher exchanges and similar sources where a formal agreement is involved. Additionally, there should be a close coordination between the TBVO and the Technical Inquiry Service which has a system that will permit more systematic (and automatic) record keeping of technical assistance inquiries.

As Phase II is implemented, involving those technology transfer mechanisms which are difficult to identify and track, researchers, branch heads and division heads will have to be more actively involved. This means that an award program will have to be highlighted and implemented early enough so that it can serve as a stimulus for a positive action on the part of NREL researchers.

There remains the issue of how to conduct data collection from users of the NREL technology. This responsibility should be vested with the Technology and Business Ventures Office, but the TBVO may not do the data collection. The TBVO might find it useful to undertake some client satisfaction surveys for program evaluation and assessment purposes. Given the fact that there are a limited number of CRADAs, licenses, subcontracts and similar formal agreements, it is possible that TBVO could undertake follow-up activities in these areas. However, as one moves into the more difficult mechanisms such as technical assistance and informal collaboration, it is more likely that a third party should be involved in the follow-up and determination of benefits. 


\section{Implementing the Svstem}

The system should be implemented in two phases. The first phase could be implemented as soon as the necessary policy has been put in place and initial steps taken to provide the resources to both the Technology and Business Ventures Office and the division Technology Transfer Representatives. Phase I will be directed at the formal agreements, and will have only modest impact upon most researchers except where they may be acting as a Principal Investigator on a project that involves subcontracts, Work for Others, and the like. Most of the burden at this phase will fall upon the Technology and Business Ventures Office, a small amount on procurement with some on branch heads or division directors and division Technology Transfer Representatives.

Phase II which completes the full implementation will involve virtually all professionals within NREL and should be undertaken only after an awards system has been put in place, and the necessary orientation of managers and professionals accomplished throughout NREL. 


\section{Chapter 4}

\section{A Practical Approach to Implementation}

Chapter 3 described a detailed system for a benefits tracking system and how it could be implemented--from an "ideal" perspective. As the world teaches us, the ideal rarely is achieved. Such was the case here, as events intervened to prevent implementation as originally proposed. The retirement of the NREL Director, nationwide search for a successor, and full establishment of a new Director consumed the better part of a year. In order not to lose valuable momentum, the study was modified to conceptually test the proposed tracking system through interviews with key NREL officials, including the Division Technology Transfer Representatives, who would be essential to useful data collection. An appropriately altered system would then be given a full scale test through an extensive survey of users of NREL technology using sampling or leads based upon the various technology mechanisms.

It was recognized that a serious effort must be made to clearly determine what information can be obtained through regular sources such as periodic reports or data bases. Interviews were conducted with senior representatives from the following NREL offices: Subcontract Administration, Corporate Communications, Conference Administrator, Technical Inquiry Service, Human Resources Office, and the Education and Special Programs staff. An assessment was made about information that would be available based upon either the data bases or periodic reports received by these organizations.

One of the largest potential sources of information consists of officers responsible for subcontract administration. Arrangements were made for the Technology and Business Ventures Office to receive copies of subcontract summary sheets for entering into the NREL technology transfer data base. This "preliminary information" is important because it permits follow-up on a statistically valid sampling basis.

Reviews with the Division Technology Transfer Representatives revealed that it would be desirable to revise the original approach by substituting face-to-face interactions on the part of the Division Technology Transfer Representatives in the place of any "reporting form" put down to researchers. NREL would still retain the goals and guidelines developed for use on technical assistance, informal collaborations and professional or trade association meetings. These three are 
mechanisms upon which the Division Technology Transfer Representatives will concentrate. The Division Technology Transfer Representatives will help researchers become more sensitive to recording technology transfer events or activities--especially the Principal Investigators. This will help researchers understand the utility and desirability of reporting technology transfer activities.

The Technology and Business Ventures Office issued guidelines concerning the roles and responsibilities of Division Technology Transfer Representatives. The purpose was to provide both guidance to the representatives and to provide stronger institutional support for this function within the various divisions. The Technology and Business Ventures Office instituted a regular feature on the monthly NREL newsletter, "Lab Talk," focussing on small technology transfer success stories.

\section{Laving the Groundwork: Assessing NREL Sources}

The interviews and discussions with NREL representatives of the subcontract administration, corporate communications, conference administration, human resources, education and technical inquiry functions, the division Technology Transfer Representatives, and staff of the Technology and Business Ventures Office--all clarified in greater detail what data useful in benefits tracking would be available from these sources.

\section{Mechanisms for Which the Technology and Business Ventures Office Currently Records Information}

The NREL Technology and Business Ventures Office collects information, and is the central repository (in most instances) for six of the technology transfer mechanisms: (1) Cooperative Research and Development Agreements (CRADAs), (2) licenses, (3) Work for Others (i.e. reimbursable work for organizations outside of NREL), (4) formal facilities use agreements, (5) subcontracts (accessed through the contracts office), and (6) spinoff companies.

In the first four instances, the Technology and Business Ventures Office is the principal repository for the data, and they have been keeping records for these four mechanisms for two years. Since the number of CRADAs, licenses, Work for Others agreement, and formal facilities use agreements is relatively small, it is possible for this office to follow-up to determine benefits from principal contacts in each of these categories. The TBVO also receives copies of the 
summary sheets on each NREL subcontract as it is closed out. It would be desirable for the TBVO to take a sample of these to follow up with subcontractor contacts concerning benefits information. Finally, the TBVO keeps an informal list of companies spun-off from NREL (or SERI). A follow-up could be conducted by the TBVO. NREL files on spinoff companies could be supplemented by an informal survey annually on the part of TBVO through checking with the division Technology Transfer Representatives.

\section{Data Recorded Elsewhere Within NREL}

The two principal technology transfer mechanisms recorded within NREL but outside of TBVO are lab-sponsored conferences or workshops and researcher exchanges. The first is held at Conference Services which maintains records in considerable detail to include name, affiliation and address of participants. TBVO could review these on an annual basis and conduct a sample follow-up of participants.

Information on researcher exchanges is the responsibility of the NREL Human Resource office. They maintain records on formal researcher exchanges. Again, there is sufficient data from which TBVO could annually review these records and conduct a sample--probably concentrating upon those researchers from industrial organizations.

\section{Data Not Svstematically Recorded in NREL}

There are five technology transfer mechanisms for which data is not systematically recorded across NREL. In some instances data relating to these mechanisms may be included in weekly or monthly activities reports within the technical divisions. On the other hand, even where the reporting appears to be most complete, the division Technology Transfer Representatives indicate that there probably is considerable activity which never sees the light of day in this type of report. Those mechanisms are: (1) professional or trade association meetings, (2) technical assistance, (3) informal collaborations, (4) researcher publications, and (5) education and training. The primary challenge to instituting a recording/reporting system for these five categories is that it depends upon the initiative of the respective researchers at NREL to do this on some periodic basis. What is lacking is an incentive system with top management support for researchers to record the fact of a technology transfer activity related to one of these five mechanisms which can be reviewed later and sampled. Experience at NREL 
demonstrates that the requirement for such recording in a top-down fashion rarely captures more than a small percentage of these activities--and typically, the function gradually fades away.

At first glance, it might appear that researcher publications should be easy to track. This is not the case. Although there are formal distribution lists for NREL technical reports, these tend to be DOE program offices and subcontractors who are closely involved in a particular project. Rarely are there distribution lists for journal articles except as they might be kept on an ad hoc basis by researchers themselves. Given the small likelihood of tracking benefits compared to the effort required, it was decided to postpone further work on this mechanism as not costeffective at this time. However, it is recommended that an annual examination be undertaken of the Science Citation Index to assess the contribution of NREL science papers among peer-reviewed journals. An exploratory review suggests this can be an important indicator of usefulness and acceptance within the scientific community.

The category of "Education and Training," has not been well-defined by DOE, but could be followed up as one finds some baseline of participants. It does not seem useful to track DOE training programs limited to DOE or Lab personnel, nor education/training programs attended by Lab personnel. The one element of "Education and Training" that may hold promise of benefits is adjunct professorships or thesis advisor activity by NREL researchers. This is even more difficult to track (e.g. influence upon students by their NREL professors). Again the pursuit of this avenue at this time was determined not to be cost-effective.

In each of these five categories of technology transfer mechanism, once a means has been established to determine that a technology transfer activity has occurred, it is possible to sample these activities and then follow-up with either mail or telephone interviews. Usually, it is better to undertake telephone interviews of a standard nature which provides better data and usually a higher response rate.

In any case, these five mechanisms which are not systematically recorded now, can be best approached with specific orientation of senior management, their initiation of an appropriate incentive system, and continuing feedback and management support. 


\section{Feasibility for Acquiring Data}

Of the thirteen technology transfer mechanisms, there is sufficient recording of information currently so that useful information can be collected on the following eight mechanisms--primarily because there is a system in place somewhere within NREL from which preliminary data can be collected and from which it is possible to develop a useful sampling strategy, to be followed by appropriate follow-up with the user organizations. These are:

- Cooperative Research and Development Agreements

- Licenses

- Work for Others

- Facilities Use

- Subcontracts

- Spinoff Companies

- NREL-sponsored Conferences or Workshops

- Researcher Exchanges

Fundamentally, each of these technology transfer mechanisms can have useful information collected in the fashion described above under the "ideal" system for collecting information.

Although a number of those mechanisms not systematically recorded currently, professional and trade association meetings, technical assistance, and informal collaborations are important technology transfer activities at NREL. It is possible to collect data on these, but they cannot be sampled statistically since there is no clear base population. One can use leads from NREL Principal Investigators as a means to explore the nature and extent of benefits from these less-formal means of transfer.

\section{Testing the Data Acquisition Process}

NREL need not await the ideal circumstances before collecting data, at least on a test basis, of most of those technology transfer mechanisms--either for which data is now being collected or for which it is not systematically collected. There are alternative means available that can provide useful information on the benefits of NREL research. 
As noted above, there are two mechanisms that it is best to omit at this particular point because possible follow-up does not appear to be cost-effective at this time: (1) researcher publications, and (2) education and training.

\section{Mechanisms for Which Data is Currently Recorded by the NREL Technology and Business Ventures Office}

Since the Technology and Business Venture Office is the principal repository of information on CRADAs, Licenses, Work for Others agreements, and facilities use agreements, it is relatively easy for them to provide the basis from which the users of NREL technology, through any one of these mechanisms, can be appropriately followed up through a structured telephone interview. None of these mechanisms includes such a large number of instances that it would be necessary to take anything less than a hundred percent sample. This could be managed as follows:

(1) Take a $100 \%$ sample of all CRADAs established in calendar years 1991, 1992, and 1993. In most instances, these CRADAs run for at least a year, and one needs a minimum of twelve months following conclusion in order to obtain results.

(2) Take a $100 \%$ sample of all licenses executed during calendar years 1991, 1992, 1993 and 1994. They should be reviewed to determine whether or not the particular technology license is relatively close to potential commercialization. Usually, technology in a license agreement is closer to commercialization than it might be in a CRADA.

(3) Do a follow-up of $100 \%$ of all Work for Others Agreements with nonfederal organizations and excluding foreign governments. This followup should include calendar years 1992 through June of 1995. It should be noted that these are separate contracts and not agreements as part of a cost-shared contract.

(4) Conduct a follow-up of $100 \%$ of any formal Facilities Use Agreements. It should be noted here, again, as above that only formal Facilities Use Agreements would be included. It is recognized that there have been informal agreements for short-term use in the past, but these are gradually being phased out. 
(5) The Technology and Business Ventures Office has an agreement with the NREL Contracts Office that summary sheets at the time of closeout of any subcontract will be forwarded to the TBVO. These should be reviewed annually and those contracts which are cost-shared for technology development should be used as the basis for conducting a sample. Initially, this should be limited to calendar years July 1991 through June of 1994 , using a 10 percent sample or a minimum of 30 potential respondents. Like licenses, subcontracts need about twelve months to assure some kind of technology transfer results.

In each instance of the five mechanisms described above, the organization or individuals who are involved in the follow-up telephone interviews should touch base with the Principal Investigator or researcher responsible for liaison with the user organization to identify any points of concern for contacting the users so as to avoid unnecessary irritation.

Finally, the TBVO maintains and informally tracks spinoff companies from NREL. A 100 percent sample is appropriate here, with follow-up of the primary contacts in these organizations.

\section{Data on Mechanisms Recorded Elsewhere Within NREL}

As noted earlier, the Conference Services Organization within NREL has extensive records on NREL-sponsored conferences or workshops, including the names, affiliation and addresses of participants. It is possible for the TBVO to sample as many as 30 participants from calendar year conferences or workshops held during 1993 and 1994. A preliminary screening identified 21 such conferences which can be further winnowed based on consultation with the division Technology Transfer Representatives to anywhere from seven to ten such conferences. From this group it is possible to take a sample of approximately 30 participants to use as a baseline for follow-up telephone interviews.

Researcher exchanges, which are a responsibility of the Human Resource Office for documentation, can be sampled, using a relatively small sample of approximately ten participants (primarily from industry) selected from the formal exchange agreements. It would be desirable that this sample be drawn from those industrial participants who spent at least one month duration at NREL during calendar years $1991,1992,1993$, or 1994 . Again, timing is of the essence since 
approximately twelve months should have elapsed prior to trying to determine the results with respect to these exchanges.

\section{Activities on Mechanisms Not Svstematically Recorded at NREL}

Of the three remaining mechanisms: (1) professional and trade association meetings, (2) technical assistance, and (3) information collaborations, there is no baseline from which to select a statistically acceptable sample. Since these activities are not recorded, one does not know the baseline or the percentage of the totality of technology transfer activities related to these respective mechanisms. An interim measure which can provide useful information (even though it cannot be extrapolated statistically) is to ask the division Technology Transfer Representatives to survey their researchers to obtain leads from which samples of users of NREL technology can be derived.

Assuming that such leads can be developed from NREL researchers [based upon past experience at NREL], it is proposed that samples for telephone interview follow-up consist of the following:

(1) Professional/trade association meetings,

(2) Technical Assistance,

(3) Informal collaborations. 


\section{Chapter 5 \\ The Survey of NREL Technology Users: \\ A Full Scale Test}

This chapter summarizes the results of the survey of those who have used NREL technology and/or been involved in collaborative activities to further technology development and its commercialization. The inquiry systematically approached non-NREL researchers to obtain their perspectives on the process of transferring technology with which they were involved and the benefits received by their organization from the collaboration/contact with NREL researchers.

The respondents represented a wide array of transfer mechanisms: licenses, cooperative research and development agreements, subcontracts, technical assistance (including informal collaboration), work for others, post-doctoral researchers in residence, visiting researchers, participants in NREL-sponsored conferences or workshops, and companies that have spun-off from NREL. (See Annex for the Methodology and Survey Instruments).

\section{The Technology Transfer Process}

During the interviews with users of NREL technology, seven questions were asked about the technology transfer process. These questions were directed to individuals who had been involved in either one of the formal agreements (such as a subcontract, CRADA, license, or Work for Others) and those who had been on the receiving end of technical assistance. The total number of interviews where these questions were asked was 106 out of the total of 156 .

The first question asked respondents was whether this had been their first contact with NREL. Slightly over a third (34 percent) answered "yes," while 66 percent said "no." In the follow-up question as to who made this contact, 48 percent responded "a company officer" while 28 percent indicated that "it was a scientist or principal investigator." The remainder had done business with NREL before, had been former SERI or NREL employees, had answered a request for proposal or NREL had made the initial contact. The third question in this series asked whether or not it had been company policy or a new initiative in making the contact. Nearly three-quarters ( 73 percent) said "it had been company policy" while 14 percent indicated that it had been "a new initiative" on their organization's part. Others indicated that the contact had been in response to a request for proposal or that they had known someone at NREL. 
The fourth question addressed how easy it was for the respondent to contact NREL. Fully 97 percent of the respondents indicated that it was very easy, easy, or not difficult. Among this group, 76 percent had indicated that it was either easy or very easy to make this contact.

The fifth question dealt with how long it took NREL to respond to the organization's initial inquiry. Slightly more than one-third (34 percent) indicated that there was an immediate response, while 46 percent said that it was only a short time or a few days. Longer response ranged anywhere from several months (7 percent) to up to a year ( 8 percent). In the latter case, the respondents were addressing the completion of a formal agreement--typically a subcontract or CRADA. In later comments, a number of these noted that this timeline had improved considerably from the first time that they had made contact with NREL.

The sixth question was directed to how easy it was to share information in their respective relationships. Among the respondents, only five percent indicated that this was not applicable to them, while 81 percent indicated that the sharing of information was easy, fine, very satisfactory or no problem. Fourteen percent indicated that they had had some kind of problem--typically in dealing with intellectual property rights as part of a negotiation concerning the CRADA, subcontract or license. (Recall that 40 percent of all respondents were involved in some kind of formal agreement with NREL).

The seventh question relating to the technology transfer process asked how effective they perceived the subcontract to be for technology transfer. Only 35 percent answered this particular question. It should be recognized that fewer than 40 percent of the respondents were involved in some kind of subcontract activity. Among the 35 percent of the respondents who answered this question, 78 percent indicated that it was good, very good, or an excellent means of technology transfer. Twenty-two percent did not believe it was particularly effective. More often than not, those who felt that it was not an effective transfer mechanism were considering transfer from NREL to their organization. A number specifically commented later that they felt their relationship with NREL did not involve technology transfer, except from them to NREL.

In conclusion, it seems clear that the bulk of contacts made by organizations with NREL resulting in either technical assistance or some formal agreement started with some previous contact with the organization. In nearly three quarters of the cases it was the company or organizational policy to seek technology from external 
sources--in this case NREL. Most respondents found it easy to contact the individual or group whom they wished to have discussions with at NREL and most (80 percent) felt that the response rate was excellent. Only 14 percent had any discomfort with sharing information during their relationship with NREL.

\section{The Benefits of Technology Transfer}

The issue of benefits flowing from NREL research by these "users," was approached from several perspectives. First, respondents were asked to estimate contributions to their sales or savings as a result of the interaction with NREL. "Savings" was defined as savings in process, materials, utilities, personnel, dead ends avoided and the like.

Respondents also were asked about any technical benefits that resulted and which could not be estimated in a monetary sense. These included such considerations as an increase in their organization's technical capability; access to equipment, tests, or skilled individuals; avoiding research "dead ends" (which could not be monetized); and the speeding of the development process.

Respondents were also asked to describe other, less tangible benefits such as an improvement in the company's image, a boost to company morale, improved credibility of their product or process, and contributions through improved contacts and marketing ability.

Finally, respondents were asked to estimate company or organizational investment in the particular technology in which they had partnered with NREL.

Nearly two-thirds (65 percent) of the respondents who had formal relationships, technical assistance relationships or were spinoff companies from NREL were able to make estimates of contributions to sales or savings and to company investment. Approximately one-fourth of those who did not make an estimate indicated that they could not make such an estimate or that the information was proprietary; the other three-fourths who did not make such estimates indicated that there had been no sales or savings or "none yet," because the technology had not reached the point where it was being commercially applied. 


\section{Contributions to $\underline{\text { Sales }}$ or $\underline{\text { Saving }}$}

Seventy-three of the respondents provided estimates of contributions to sales or savings in their respective organizations. The combined total of sales and savings from these respondents amounted to $\$ 713,401,000$. Several replied that the sales or savings had totaled "millions" but they were unable to be more distinct than this, and therefore their answers were not included in the total.

\section{Company Investment}

Here seventy-two respondents--nearly 50 percent were able to estimate their company investment in the shared technology. Slightly more than one-third of the total were unable to make an estimate, provided no answer or indicated that that information was proprietary. There was a total investment by these 72 respondents from their companies of $\$ 104,273,700$. Again, several replied "millions," but these could not be included in the totals.

\section{Technical Benefits}

The most often mentioned technical benefit was that of an increase in the organization's technical capability, where 53 percent of the respondents indicated that this was an important benefit. Fully 43 percent of the respondents indicated that access to equipment, tests, or NREL researchers was an important technical benefit; and 38 percent indicated that avoiding research dead-ends proved valuable to them. Just over 5 percent of the respondents indicated that their cooperation with NREL made their product more competitive or opened up a new line of business.

\section{Other Benefits}

Just over one-third ( 36 percent) of those querried, indicated that the relationship with NREL had contributed to an improvement in the company's image. Most who noted this indicated that it was the association of the company or organization with NREL that reflected favorably on the company. Another 21 percent indicated that this association boosted company morale--partly because of the stimulation technologically of the organization's researchers, and the association with NREL researchers. "Credibility" was an important benefit described by 15 percent of the respondents. Typically, their comments indicated that the fact their product or process had been examined, tested, or in some fashion shared with 
NREL lent credibility-one might almost say comparable to a "Good Housekeeping Seal of Approval." Finally, seven percent of the respondents indicated that through their association with NREL they were able to make contacts with potential customers which proved helpful or were able to improve the marketing of their product or process.

\section{Satisfaction With Cooperative Efforts}

Those respondents who had had a relationship with NREL involving a formal agreement or technical assistance were asked a series of seven questions related to their relative satisfaction with that relationship. On each question respondents were asked to rate their relative satisfaction on a five point scale as follows: 1-very dissatisfield; 2-dissatisfield; 3-neutral; 4-satisfied; and 5-very satisfied; or not applicable.

The first question was "Overall, how would you rate your working relationship with NREL?" There was considerable satisfaction among the respondents, 91 percent claiming that they were either satisfied or very satisfied with this relationship.

The second question was "How would you rate NREL's level of performance in providing your organization technical products/services?" Again, there was considerable satisfaction with 72 percent of the respondents indicating they were satisfied or very satisfied; although 17 percent indicated that this was not applicable.

The third question asked, "Overall, how would you rate NREL's negotiation and execution process?" Here there was less satisfaction although 25 percent of the respondents believed that this was not applicable to them (probably reflecting the fact that they were not involved in some type of formal agreement). Those who answered satisfied or very satisfied constituted 45 percent, while only 8 percent were very dissatisfied or dissatisfied. Twenty-one percent indicated that they were neutral on this particular question.

The fourth question asked respondents "How would you rate NREL's performance in timeliness to process/prepare/negotiate the partnership agreement?" Again, nearly one-fourth ( 22 percent) indicated that this was not applicable, while 48 percent were satisfied or very satisfied, 17 percent felt neutral on this and 13 percent were either dissatisfied or very dissatisfied. 
Next, the respondents were asked "Did you meet the objectives you established for your project with NREL?" Eighty-one percent answered "yes," 12 percent "no," and 7 percent believed the question was not applicable.

Next, the respondents were asked "Would you be willing to work with NREL again?" All but one respondent answered "yes," and that respondent replied "Maybe."

Finally, the respondents were asked "Would you recommend working with NREL to another organization if that opportunity arose?" One hundred percent answered that they would make such a recommendation.

\section{Lessons Learned}

Two questions were posed to elicit comments on how NREL's technology transfer process might be improved. (1) How can NREL improve working with industry?; and (2) What has been learned from this experience of transferring technology?

\section{How Can NREL Improve Working With Industrv?}

This was an open-ended question so that respondents were able to provide any suggestions that came to mind. The two issues or suggestions that stand out are: (1) "shorten and improve the process for formal agreements" (27 percent); and (2) "be sensitive to industry needs; timeliness, and importance of the bottom line," (21 percent).

The third most favored suggestion was "provide better communications to industry and the public," ( 20 percent). Here the respondents directed their attention to providing more detailed information on the capabilities of NREL so that industry would be aware of those capabilities and also to provide more information to the public so that the public might be more aware and knowledgeable of NREL programs and their value.

The fourth most expressed opinions were simply complimentary remarks about the excellence and cooperative nature of NREL researchers; while the fifth most favored suggestion (6 percent) suggested that there was need for further technical development toward commercialization--principally that NREL should be supplied with the resources to move the technology a bit further on the spectrum toward commercialization. 


\section{What Has Been Learned From This Experience of Technology Transfer?}

By far the bulk of remarks here (77 percent) were of a positive, complimentary nature. For example, respondents observed, with respect to their relationship to NREL: "Very cooperative," "an open door," "high level of competence," "great experience," "responsive, "and, "interaction among the parties (i.e. researchers) is critical."

Another 13 percent indicated their belief that the public/private partnership can work and is important. Five percent observed "one needs patience to make technology transfer work." And another five percent indicated that intellectual property often can be difficult to deal with (especially in the formal agreement type of relationship).

\section{Other Means of Technology Transfer}

As noted earlier there were three other types of technology transfer which were explored, using an interview instrument that was quite different from those used in interviewing respondents who had formal agreements or technology assistance. These other mechanisms of technology transfer for which interviews were specifically targeted were: spinoff companies, visiting researchers or postdoctoral researchers, and NREL conference or workshop attendees. (See Annex for the interview instruments used.)

\section{Spinoff Companies}

Apart from questions relating to monetary or technical benefits and company investment, the questions put to respondents from spinoff companies focussed on three areas: (1) the circumstances that led to the establishment of the company; (2) the nature of the company's relationships with NREL ; and (3) those NREL technical services that have proved helpful to the company.

The circumstances which led to the establishment of the company in two-thirds of the cases were characterized as "program reductions," "a shift in SERI/NREL priorities," and "a technology not being pursued by SERI/NREL." In these instances, NREL researchers chose to take an entrepreneurial route and to establish their own firms (perhaps with others as well) to continue to pursue technology which they believed to be important and had potential for commercialization. One respondent indicated that the company he represented had 
existed before SERI was established but that a number of senior NREL researchers had joined the firm and therefore "spunoff." Another indicated that his company got started with Department of Energy funding (although this did not come through SERI/NREL) and that several senior people in their organization had come over from SERI/NREL.

All the respondents indicated that their respective companies had at least some technical relationship with NREL, and 83 percent still did. Typically, these consisted of continuing relationships with NREL researchers with whom they were either personally or professionally involved. This tended to be on an informal collaborative fashion rather than through a formal structure. On the other hand, fully 83 percent of the firms had or had in the past a subcontracting relationship with NREL.

With respect to those technical services from NREL which have proved helpful. fully two-thirds indicated that they found access to NREL researchers (even in an informal fashion) very helpful, and two-thirds had made use of access to the NREL library. Half indicated that technical services especially helpful were access to equipment and to NREL testing capabilities.

\section{Visiting Researchers/Postdoctoral Researchers}

Interviews with these respondents concentrated upon what attracted them to NREL, the benefits they perceived of their assignment at NREL, and what they might take back to their respective organizations. In addition, they were asked about the length of their tour at NREL and whether or not their assignments involved any work with industry.

The length of their assignment at NREL averaged 25 months, but ranged from a low of five months up to a high of five years. Forty percent of the respondents indicated that their assignment did involve work with industry, another twenty percent said that it involved a little work with industry, while forty percent indicated that there was no work with industry at all.

Eighty percent of the respondents were attracted to NREL because of what they characterized as the opportunity to do research in an area of particular interest to them. Another aspect attracting them was the reputation of NREL as a research institution--fully forty percent said they were attracted by that. Another twenty percent said that they were attracted by the NREL mission to facilitate the 
increase of technological capability in renewable energy industries. As in the previous question, respondents gave multiple answers to the question about the berefits to them of their assignment at NREL. Ninety percent said that they felt a key benefit was the "good opportunity" to undertake research; and 70 percent cited "excellent colleagues" as a primary benefit of their assignment. Sixty percent indicated that the development of skills as well as career development were an especial benefit, while 40 percent noted the excellent equipment and research support that was given to them as visiting researchers or postdoctoral researchers.

"What can you take to your organization that will be useful?" Because most (70 percent) of the respondents were in some type of career transition as a visiting researcher or postdoctoral researcher, they could not answer this question with any firmness. They were in a circumstance in which they had not made a decision as to whether or not they were going back to a particular position they had before coming to NREL nor had they determined a new position for which they were striving. The other 30 percent essentially said that they "could apply their new knowledge and experiences to the job" irrespective of whether they were going to a new position or returning to another organization.

\section{NREL Conferences or Workshops}

The focus with this group of respondents was fourfold: (1) to understand what the attendees believe they took away personally from the conference or workshop; (2) to understand what they perceive to be the usefulness of attending the particular conference or workshop in terms of benefits to their own organization; (3) to discover whether or not they had continued any further technical contacts with NREL; and (4) to ask whether or not they would be interested in attending a similar NREL conference or workshop in the future.

Most ( 71 percent) characterized the value of the conference or workshop to them as being "gaining perspective," or "an overview of the state of the technology." Nearly half ( 47 percent) pointed to "advances in the technology," as a primary benefit while 38 percent viewed the networking with other researchers and technical representatives, and contacts of a technical or commercial nature as being particularly valuable. Similar to this benefit, 29 percent found the discussions and the interchange with peers and experts as a useful benefit. Others described "understanding the potential commercialization" of a particular technology as well as the "evaluation of the programs and technologies" to be of substarisial benefit. 
In response to the query about what the attendee could take back of value to his or her organization, several indicated that attending the conference helped them to initiate a company program whereas several others noted that they had instiruted the process by which they would eventually receive a contract from another organization. One indicated that his organization was able to put together a collaboration. Another respondent set up a lab using the technology which had been under discussion. Half of the respondents cited that the conference or workshop was particularly good to bring their awareness up to date and to provide them information on NREL programs in which NREL had collaborated with industry and the universities. Others ( 29 percent) found it useful to be able to discuss company interests with other attendees--several even indicated that this opportunity had an impact on their sales (one individual indicating that there had been a 15 percent increase in sales as a result of these contacts). Nearly one-third (29 percent) of attendees cited the value of understanding the potential of research and development discussed at the conference and also the ability to avoid certain R\&D pitfalls. Others ( 20 percent) cited potential prospects and commercialization possibilities as distinct benefits, while 18 percent found the assessment of the value of the technology under discussion as particularly helpful.

Nearly two-thirds (65 percent) of the respondents indicated that they had had further technical contacts with NREL. Among the 35 percent who had none, half represented respondents who had either retired or moved into another technical area with their company--i.e. one which was different from the conference or workshop that they had attended. Among those answering "yes," 54 percent said that they had continued technical contacts through dialogue with NREL researchers or visits. Discussion via telephone, reports, testing, and FAX were cited by 29 percent of the respondents who had continued technical contacts, while 24 percent had a continuing contact through a formal agreement such as a CRADA or a subcontract.

Finally, in response to whether or not they would attend a similar NREL conference in the future, 82 percent indicated that they would; and among this group, many commented on the value in terms of their willingness with such comments as "absolutely;" "vital," "extremely useful," "very beneficial," --all seeing it useful for both overview update and valuable contacts. Among the 18 percent who said they would not attend a similar conference, the reason was because they were now in a different technical area and would not attend a conference on the same technical subject as the one which was being discussed. 


\section{Recap of Survey Results}

There were 156 completed interviews.

\section{The Transfer Process}

o 106 respondents were asked about the transfer process.

- Two-thirds had previous contact with NREL.

- $\quad 97$ percent had no difficulty contacting NREL.

- 80 percent reported NREL response time to be short.

o 81 percent found no difficulty in NREL's sharing information.

- 78 percent believed the cost-shared subcontract to be a good transfer mechanism.

\section{Benefits of Technology Transfer}

- 47 percent of the respondents provided estimates of NREL contributions to sales or savings aggregating over $\$ 713$ million.

- 46 percent estimated an aggregate of over \$104 million in company investment in the shared technology.

- 53 percent reported an increase in technical capability.

o 43 percent valued access to unique equipment, tests, or NREL researchers.

- 38 percent reported avoiding research dead-ends.

- 72 percent reported "other benefits" e.g. improved image, boosted morale, or gave greater credibility to the company's product or process. 


\section{Satisfaction with Cooperative Efforts}

- $\quad 91$ percent rated working with NREL as "satisfied" or "very satisfied."

- $\quad 87$ percent rated NREL's technical performance as "satisfied" or "very satisfied."

- 60 percent rated NREL's negotiation/execution process as "satisfied" or "very satisfied."

o 62 percent found NREL's timeliness in processing a partnership agreement as "satisfied" or "very satisfied."

- $\quad 87$ percent felt they had met their objectives.

- 100 percent would recommend working with NREL to another organization.

\section{Lessons Learned}

- 48 percent believed that NREL could improve its working relationship with industry by: (1) improving the process for formal agreements; and (2) showing more sensitivity to industry needs.

o $\quad 77$ percent made complimentary remarks about their work with NREL. 


The Positive Climate for
Technology Transfer at NREL
NREL'S MISSION
Acknowledgement of Technology Transfer as
Emportant element of one's job
More than by $75 \%$ involvers monthly or more
often in technical assistance
Ability to clearly define the positive
impact of tech transfier

A System for Identifying, Tracking
and Evaluating Research Benefits
CRADAs
Cost-shared R\&D subcontracts
Technork for Others Agreements
Post-doctoral/visiting scientists collaborations
Attendees at NREL Conferences/Workshops
Spin-off companies

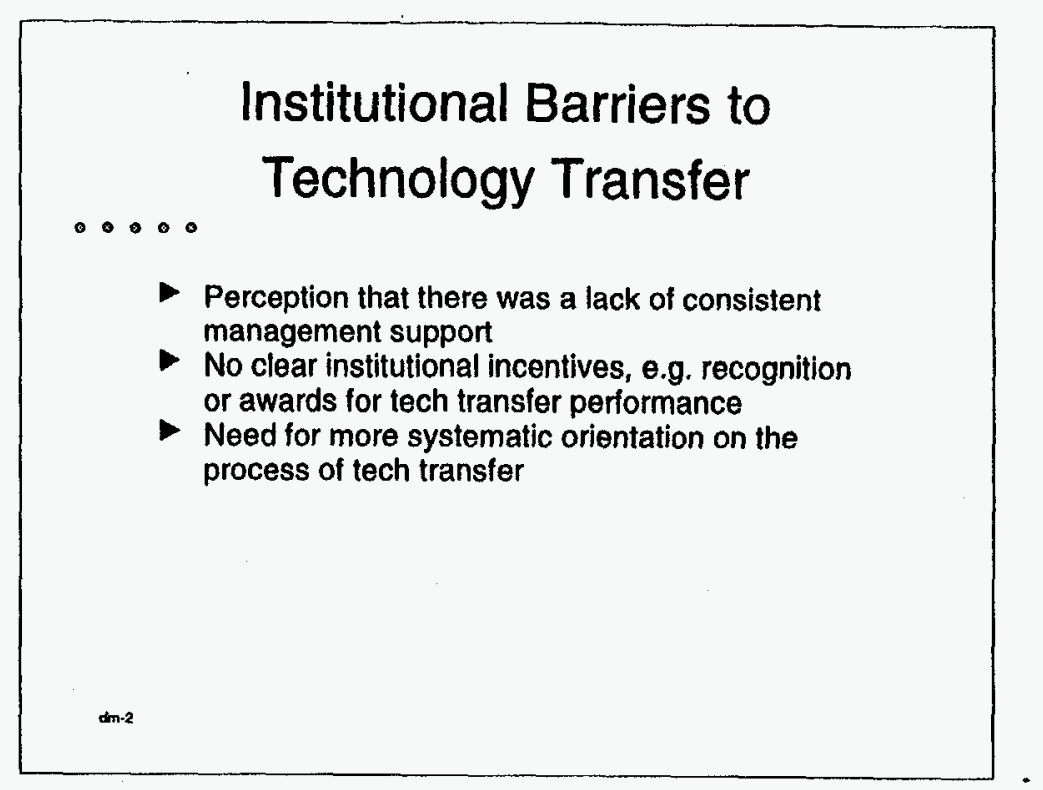

\section{The Transfer Process}

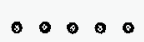

106 respondents were asked about the transfer process

- Two-thirds had previous contact with NREL

97 percent had no difficulty contacting NREL

80 percent reported NREL response time to be short

81 percent found no difficulty in NREL's sharing information

- 78 percent believed the cost-shared subcontract to be a good transfer mechanism

am-4 


\section{Benefits of Technology Transfer}

$\therefore 0.0$

-47 percent of the respondents provided estimates of NREL contributions to sales or savings aggregating over $\$ 713$ million

- 46 percent estimated an aggregate of over $\$ 104$ million in company investment in the shared technology

- 53 percent reported an increase in technical capability

43 percent valued access to unique equipment, tests. or NREL researchers

- 38 percent reported avoiding research dead-ends

72 percent reported "other benefits" e.g. improved image, boosted morale, or gave greater credibility to the company's product or process

\section{Satisfaction with Cooperative Efforts}

$\because \ldots$

- 91 percent rated working with NREL as satisfactory or very satisfactory

- 87 percent rated NREL's technical performance as satisfactory or very satisfactory

- 60 percent rated NREL's negotiation/execution process as satisfactory or very satisfactory

- 62 percent found NREL's timeliness in processing a partnership agreement as satisfactory or very satisfactory

87 percent felt they had met their objectives

100 percent would recommend working with NREL to another organization

ance

\section{How Can NREL Improve Working with Industry?} $\because \cdots$

Shorten and improve the process for formal agreements

- Be sensitive to industry needs, e.g. timeliness and the importance of the bottom line

- Provide better communications to industry and the public

\section{Other Means of Technology Transfer}

- 0000

- Spin-off Companies

- Enthusiasm for commercialization of technology

- Continued technical relationship via colleagues,

use of equipment - or access to the library

- Visiting/Post-doctoral Researchers

- Half involved in work with industry

- Skills and contacts applicable to next technical challenge

- NREL Conferences/Workshops

- Perspective, overview, update

- Networking--both with NREL scientists and others

- Continuing technical contact with NREL

- "Vital," "extremely useful" 


\section{Lessons Learned}

$\therefore 0.0$

- Benefits of laboratory research to industry partners can be identified and documented.

A systematic approach will yield tangible and

significant benefits from the informal mechanisms

of tech transfer (technical assistance, conferences,

and collegial collaborations).

- Industry partners place considerable value on the intangible benefits of cooperation -- image,

credibility, enhancement of staff skills

an-9 



\section{Chapter 6}

\section{Observations and Conclusions}

The broad sweep of the data from this study and its component inquiries reveal the following.

First, significant value accrues from NREL research and resultant technology. This strengthens American industry toward effective commercialization of renewable energy products and processes, and thereby reduces U.S. dependence upon foreign energy sources. It also reaffirms the fundamental vision of NREL as a key actor in this process, filling a gap that neither industry nor universities can meet; and acts as an "honest broker" among interested parties.

Second, although further improvements can be made, NREL has notably upgraded its technology transfer program and its ability to work with industry on a more timely, effective basis.

Third, as a whole, NREL conferences and workshops, focussed on a particular technology, are highly valued and are important to bringing industry and university assets to bear on technical programs of importance to the Nation.

\section{Technology Transfer at NREL}

There is a clear eagerness among NREL researchers to facilitate the application of NREL science and technology. The survey of NREL researchers conducted at the outset of this study showed that the primary reason for their choosing to work at NREL has been to advance renewable energy technology and see it commercialized for broad use in American society. NREL researchers consistently recognized technology transfer as an important element of their respective positions.

All NREL researchers showed an awareness of the value of technology transfer to the laboratory and more broadly, to American society. 'All had at least some familiarity with NREL's technology transfer activities. However, nearly twothirds (64 percent) would like more information about NREL technology transfer-e.g. how to be more successful in the process, what others in the lab are doing, and results--especially success stories. 
Both the pilot and full-scale surveys of NREL technology users show that, although there are significant monetary benefits, the technical benefits may well prove to be most important in the long run. These tend to produce greater monetary benefits over time. For example, process improvements--especially in large-scale industry--initially require costly capitalization, training and some loss of production during the introduction phase. But, in time, the savings (and often better product), including a more competitive position, pay significant dividends. A case in point is the array of technologies for producing ethanol.

Many of the comments of NREL technology users concerning possible improvements in the technology transfer process focussed upon the time required to complete negotiations on a formal agreement (subcontract, CRADA, Work for Others or licenses). Two significant changes have been made that are alleviating this concern. First, CRADA, Work for Others, Facility Use agreements, and license negotiations have all been made the responsibility of the Technology and Business Ventures Office. Second, the NREL procurement process has been substantially reorganized and streamlined to greatly reduce the time to complete the process.

Reporting Technology Transfer Activities: Possible Management Action

The key to an effective benefits tracking system is to have appropriate means to identify when a transfer activity has been initiated so that recording or follow-up can take place. Informal technology transfer, such as ad hoc discussions, telephone consultation, brief visits and collegial correspondence often are lost unless the researcher makes a few brief notations in his/her log book. It is important that NREL management sensitize researchers to the importance of such recording for potential follow-up and benefits determination. In this survey 40 percent of all respondents included in benefits determination came as the result of technical assistance activity. And 84 percent of these respondents reported monetary, technical or other significant benefits.

The first stage of a comprehensive benefits reporting system is in place. The Technology and Business Ventures Office now maintains such a system for CRADAs, licenses, subcontracts, Work for Others agreements and Facilities Use agreements. Next, NREL needs to address the incorporation of technical assistance and informal collaboration as well as results based upon attendance at NRELsponsored conferences or workshops. This will require management consideration of the kind of suggestions outlined in Chapter 3. 
In order to promote more effective technology transfer, NREL management needs to encourage researchers through a more clearly defined system of recognition--beyond current efforts via the Federal Laboratory Consortium technology transfer awards and the R\&D 100 recognition. Appropriate recognition has been at the very heart of stimulation for researchers.

\section{Improvements in Future Survevs}

Useful surveys require a "point of origin, "--i.e. a recognized population from which to begin. The full scale test survey reported here had such populations for all of the technology transfer mechanisms included except technical assistance and informal collaboration. Since these represent a key segment of the total population to be included, it is important to establish a means of reporting such activities that will capture most or at least a representative sample of them.

The full scale test survey revealed a weakness in establishing the time frame for sampling attendees at NREL-sponsored conferences or workshops. It proved difficult for attendees to recall workshops or conferences two years or more distant in time. Better results would be obtained through follow-up within 3-12 months following a conference or workshop. In addition to the recall function, about onethird could not be reached because of telephone, company or occupational changes during the intervening one and one-half to two and one-half years since the meeting. NREL could consider having its conference services group do a follow-up similar to the test survey on a sample of attendees as a regular function.

This survey excluded any technology transfer benefits from the involvement of NREL staff in collegiate-level teaching or supervision of theses. NREL might explore this through an intern or graduate student assignment.

Also excluded was how researchers' publications affected technology applications. This remains a complex phenomenon, but it would be useful to explore citations of NREL researcher-authored papers, and where known, citations of papers authored by NREL-sponsored researchers. 


\section{In Summary}

- Significant value accrues from NREL research: 73 instances of the application of NREL technology from shared research resulted in contributions to sales or savings of cooperators aggregating over $\$ 713$ million.

- NREL researchers and staff are dedicated to the advance of renewable energy technology and its commercialization.

- NREL has made notable progress in upgrading its technology transfer processes, and needs to give increased emphasis to the recognition and measurement of success. 


\section{Annex 1 \\ Methodology and Survey Instruments}

\section{General Approach to Methodology}

A standard format was used for the telephone interviews except for postdoctoral or visiting researchers, conference or workshop attendees and representatives of the spinoff companies. This was because of the significant difference in circumstances from the other types of transfer mechanisms.

The standard format was used for the formal agreement mechanisms (subcontracts, CRADAs, Work for Others and licenses) and for technical assistance. This form focussed upon (1) the process of transferring technology; (2) the benefits from technology transfer; (3) the relative satisfaction among cooperators working with NREL; and (4) lessons learned. Data from spinoff companies included information on benefits, and lessons learned.

Before any contact was made with a potential respondent, the NREL researcher most involved as the principal investigator or technical monitor was contacted to fill in gaps in information, to ascertain any sensitivities, and to let that NREL researcher know of the interview process.

\section{Selecting Respondents}

A time frame was selected for each technology transfer mechanism on the basis of capturing the best data, including technology applications that would provide evidence of commercialization. Relationships begun or completed before calendar year 1991 were excluded because experience in other agencies showed that tracking contacts that old was not very fruitful. Also CRADA and license agreements only came into play for NREL since 1991.

The specific procedure for selecting potential respondents representing each mechanism was as follows:

All licenses that were initiated during calendar year 1991 through calendar year 1994 were included. This represented a total of 8. 
All cooperative research and development agreements from the very beginning (calendar year 1991) that were initiated through calendar year 1993 were included. This was a total of 18 .

All cost-shared research and development subcontracts with commercial firms that were completed between July 1992 and December 1994 were included. This amounted to 30 such subcontracts.

Representative examples of technical assistance (informal) activities were obtained from NREL researchers through their respective division Technology Transfer Representatives. This resulted in 52 such technical assistance leads.

All R\&D Work for Others Agreements that were completed with commercial, domestic organizations from July 1992 through June 1995 were included. This amounted to 13 such agreements.

A random sample from a potential population of 41 post-doctoral or visiting researchers was taken for a total of 10 sample respondents who were at NREL between the period July 1992 and June 1995.

Twelve conferences or workshops sponsored by NREL were included that occurred in calendar year 1993 or 1994 . The groups ranged widely in the number of attendees. Only those attendees who were not from government or from universities were included so that the potential "population" from which to make selections ranged from four to a 100 , with a random selection of approximately 3 from each of the 12 conferences. The total here was 51 .

Finally, the Technology and Business Ventures Office furnished the names, addresses and contacts for spinoff companies from NREL, where information was available, on how to reach these organizations. The total for this was 6 .

\section{Response Rate}

The response rate was excellent. Among those called using the standard format (subcontracts, CRADAs, Work for Others, licenses, and technical assistance) only nine of the 115 could not be interviewed. Of these, eight were "dead-ends" where the individual or company could no longer be traced. One individual chose not to cooperate. Originally there were 121 "leads" for this group; 
six were dropped from the survey after consultation with the cognizant NREL technical monitor.

All prospective respondents among visiting researchers or post-doctoral researchers and spinoff companies did participate. Among sampled attendees at NREL conferences or workshops 31 of 51 participated. One opted out and 18 could not be located. Three other attendees from other NREL sources were included for a total of 34 participating.

\section{Interviews Completed}

Interviews completed totalled 156.

\begin{tabular}{|c|c|c|}
\hline Relationship & Number & Percent of Total \\
\hline Formal Agreements & 63 & 40 \\
\hline Technical Assistance & 43 & 27 \\
\hline Workshops/Conferences & 34 & 22 \\
\hline $\begin{array}{l}\text { Visiting Researchers/ } \\
\text { Post Docs }\end{array}$ & 10 & 7 \\
\hline Spinoff Companies & 6 & 4 \\
\hline Total & 156 & 100 \\
\hline
\end{tabular}


In:erview \#

Date

Company Technical

Contact:

TeI No.

Name oİ Company:

Adaress of Company:

Technology:

NREL Researcher Contact:

CHAPMAN RESEARCH GROUP of Iittleton, Colorado, is undertaking a study for the National Renewable Energy Ijboratory to learn (1) your reaction to the Technology Transfer Process and (2) the benefits obtained by you from the transfer of this technology.

\section{A. The Technolooy Transfer Process}

This part of the study seeks a better understanding of how the technology transier process has worked, so that NREI can continue to improve this process.

1. Was this your first contact with NREL? Yes No

2. If yes, who, within your organization made the first contact [nature of the person's responsibility and level of authority]. initiative?

3. Was it company policy to seek such opportunities or was this a new

4. Who was the Eirst NREL contact?

How easy was it to Eind out whom to contact at NREL?

5. How long did it take to obtain a response from NREI?

6. What was the result of this initial contact? subcontract; collaboration (e.g. CRADA or other joint effort); work for others, etc.?

7. Fow was NREI to work with in terms of sharing information and handling intellectual property?

8. [IF APDIICABLE) How effective is the SUBCONTRACT as a means for technology transfer? 
Dage 2

\section{Benefits}

Introcuction: What we are MOST interested in for this study of technology transfer benefits is trying to define the benefits derived from that application of the technology [currently or in the near future].

1. Benefits can be desined in a number of ways. One commonly accepted definition is in terms of money. Could you estimate [in any form] the dollar benefits the technology has brought to your company in terms of:

- SAIES?

- SAVINGS IN IA $30 R$ COSTS?

- SAVINGS IN RaD?

- SAVINGS IN TESTING?

- SAVINGS IN MATERIAIS OR UTIIITIES COSTS?

- SAVINGS IN EQUIDMENT--CADITAL OR MAINTENANCE?

NOTE: If answers are not at hand, we will be happy to call you later for them. We accept whatever you can share with us that will enable us to craw some general conclusions about eccnomic benefits.

2. Benefits can also be defined as the technical benefits--such as improved capability of researciers or other employees; access to special equipment or facilities; avoiding research or development "dead ends;" and the like. Colid vou describe any benefits of this type that can be attributed to the use of the [described] technology?

[Only for CRADEs, Iicenses, Subcontracts] Did any of your researchers spend time as a visiting scientist at NREL?

3. Benefits can inciude a wide variety of items such as employee morale, or compary image. Could you describe any benefits your company has received that might fit this category?

4. In the process of adopting the technology, what do you estimate was the company's [organization's] investment? In dollars, man days, etc.? 
¿age 3

In conclusion: Dlesse rate the following on a five point scale:

I-Very Dissatisfied; 2-Dissatisfied; 3-Neutral; 4-Satisfied;

5-Very Satisfied; OR - Not ApDlicable

A. Overall, how would you rate your working reletionship with NREL?

$\begin{array}{llllll}1 & 2 & 3 & 4 & \mathrm{NA}\end{array}$

B. How would you rate NREL's level of performance in providing your organizacion technical products/services?

1

2

3

4

$5 \quad N A$

C. Overall, how would you rate NREL's negotiation and execution process?

$\begin{array}{llllll}1 & 2 & 3 & 4 & 5\end{array}$

D. Sow would you rate NREI's performance in timeliness to process/prepare /negotiate the partnexsinp agreement? nswer by yes or No or NA, with elajoration.
1
2
3
4
$5 \quad \mathrm{NA}$

E. Did you meet the cojectives you established for your project with NREL?

$$
\text { Y }
$$

N

NA

I. would you be willing to work with NREI again?

$$
\underline{Y}
$$

N

$\mathrm{NA}$

G. Would you recommend working with NREL to another organization if that opportunity arose?
$\mathrm{Y}$
$\mathrm{N}$
NA

I. What suggestions can you make to improve NREI's working with incustry?

DLEASE STATE WIAT EAS BEEN LEAPNED EROM TEIS EXPERIENCE OF TRANSFERRING TECHNOLOEY?

CONCLUSION: THANK YOU FOR YOUR HELP. WE WIII BE SENDING YOU A SUMMIPY OE OUR FINDINGS AT TFE CONCIUSION OF TEIS STUDY. NEED COMPIETE ADDRESS: 

Interview \#

Date

SPIN-OFF COMPANY QUESTIONNAIRE

NREI Benefits Survey 1995-96

Company Contact:

Name of Company:

Telephone No.

Address of Company:

Technology :

NREL Researcher Contact:

CHAPMAN RESEARCH GROUP, InC. of littleton, Colorado, is undertaking a study for the National Renewable Energy Laboratory to learn (1) your reaction to the Tecinology Transfer Process and (2) the benefits obtained by you/your company from the transfer of this technology. explainj.

1. What circumstances led to the establishment of your company? (Please

2. What has been the nature of the company's relationship with NREI?

3. What technological resources of NREL have been helpful to the company? 
Page 2: Spin-off companies

Benezits: Introduction

What we are MOST interested in for this study of technology transfer benefits is trying to define the benefits derived from that application of the technology [curzently or in the near future].

1. Senefits can be defined in a number of ways. One commonly accepted cefinition is in terms of money. Could you estimate [in any form] the dollar benefits the technology has brought to your company in terms of:

- SAIES;

- SAVINGS IN LABOR COSTS?

- SAVINGS IN R\&D?

- SAVINGS IN TESTING?

- SAVINGS IN MATERIALS OR UTILITIES COSTS?

- SAVINGS IN EQUIPMENT--CAPITAL OR MAINTENANCE?

NOTE: If the answers are not at land, we will be happy to cail you later for them. We accept whatever you can share with us that will enable us to draw some general conclusions about economic benefits.

2. Benefits can also be defined as the technical benefits--such as improved capability of researchers or other employees; access to special equipment or faciiities; avoiaing research or development "dead ends;" and the like. Could you describe any benefits of this type that can be attributed to the use of the [described] technology?

3. Benefits can inciude a wide variety of items such as employee morale, or company image. Could you describe any benefits your company has received that might fit this category?

-What suggestions can you make to improve NREL's working with industry?

- What has been learned from this experience of transferring tecinology?

4. In the process of adopting the technology, what do you estimate was the company's [organization's] investment? In dollars, man days, etc? 
NREL Benefits Questionnaire Visiting Scientists and Post Docs

1. Name of Visiting Scientist or Post Doc:

2. Supervisor of Record:

3. Assignment at NREL:

3a. Did this involve any work with industry? What were the circumstances?

4. What attracted you to this assignment?

5. How Iong have you been at NREL?

6. What do you perceive to be the benefits from your assignment at NREL?

7. [optional] What can you take to your organization/company that will prove useful? [follow up] How might it be used? Any results to date? 
Inlerview lio.

Dה:=

\section{QUESTIOHS FOR NTTENDEES \& HREL COINEREHCES/WORKSHOES}

WREL Benelits Survey 1995-96

1. Namc/vate of Workshop:

2. NREL Techuical Coordinator:

3. Mamn/Artilintinn of Mt.Lemese

(Mail acldress. Tel No.)

1. To the bert of your recollection of that conference/workshop, what did you "Lake awaj" lrom il?

5. What: nre was this to you or your organization?

irollow-on: Nuy change in product or processiug--e.g. savings or sales: [acilitated [urther R\&D?]

6. Have you had furtier lechical contacts with NREL since the conlerence/workshop? Flease explain.

7. Would you atlend a similar Nels conference/workshop in the Iuture? Why or wing not? 


\section{Annex 2 \\ Tavles Aggregating Responses of Respondents Representing Formal Agreement Relationships and Technical Assistance}

These tables cover five key questions:

(1) How was NREL to work with in terms of sharing information and handling intellectual property?

(2) What is your estimate of benefits in terms of sales or savings derived from the application of the technology?

(3) Describe any technical benefits so derived.

(4) Describe any intangible benefits your company received.

(5) What do you estimate was the company's investment (in the process of adopting the technology)?

The numbers of respondents by class were as follows:

$\begin{array}{lc}\text { Shared-cost subcontracts } & 33 \\ \text { CRADAs } & 17 \\ \text { Work for Others } & 11 \\ \text { Licenses } & 2 \\ \text { Technical Assistance } & 43\end{array}$

Total 106

These respondents answered the "long form" interview. Others (representatives of "spinoff" companies, visiting and post-doctoral researchers, and participants in NREL Conferences or Workshops) were interviewed using a much shorter form. 
Table 1

NREL's Willingness to Share Information

$\underline{\text { Respondent Class }}$

Shared-Cost Subcontract

CRADAs

Work for Others

Licenses

Technical Assistance
\% Favorable*

100

82

100

50

95

*i.e. responded from "no problem" to "excellent"

Table 2

Estimated Contribution Towards Aggregate Sales/Savings*

Respondent Class

Shared-Cost Subcontract

CRADAs

Work for Others

Licenses

Technical Assistance
Sales/Savings (\$000)

169,652

453,695

1,880

72,825

2,514

*Estimates were made by the respondents. 
Table 3

Technical Benefits from Working With NREL

\begin{tabular}{lccc} 
& \multicolumn{3}{c}{ Technical Benefits* } \\
\cline { 2 - 4 } Respondent Class & $\begin{array}{l}\text { Extended } \\
\text { Technical } \\
\text { Capability }\end{array}$ & $\begin{array}{l}\text { Access to } \\
\text { Facilities/ } \\
\text { People }\end{array}$ & $\begin{array}{c}\text { Avoided } \\
\text { R\&D } \\
\text { Deaden }\end{array}$ \\
\hline Shared-Cost Subcontract & $69 \%$ & $33 \%$ & $31 \%$ \\
CRADAs & $65 \%$ & $76 \%$ & $35 \%$ \\
Work for Others & $54 \%$ & $73 \%$ & $54 \%$ \\
Licenses & $100 \%$ & -- & -- \\
Technical Assistance & $51 \%$ & $37 \%$ & $37 \%$
\end{tabular}

*This was open-ended. Replies have been categorized and respondents may have had more than one answer.

Table 4

Other Benefits from Working With NREL *

Respondent Class

Company

Image

Company

Morale

Company

Credibility

Shared-Cost Subcontract

CRADAs

$59 \%$

$28 \%$

$28 \%$

Work for Others

$41 \%$

$24 \%$

$24 \%$

Licenses

$9 \%$

$18 \%$

$27 \%$

Technical Assistance

$50 \%$

$50 \%$

$21 \%$

$23 \%$

$14 \%$

*This was open-ended. Replies have been categorized, and respondents may have had more than one answer. 
Table 5

Estimated Investment Made By Cooperators*

$\underline{\text { Respondent Class }}$

Shared-Cost Subcontract

CRADAs

Work for Others

Licenses

Technical Assistance
Investment $(\$ 000)$

38,383

29,301

3,817

8,750

$16,871 * *$

* Estimates were made bv the respondents.

** Note: $49 \%$ made investments in the technology averaging over $\$ 800,000$ per company. 


\section{REPORT DOCUMENTATION PAGE}

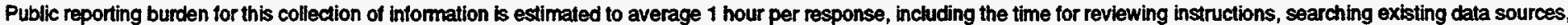

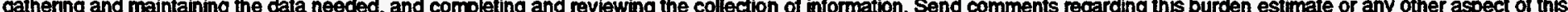

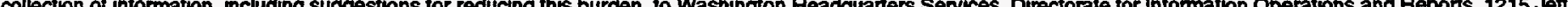

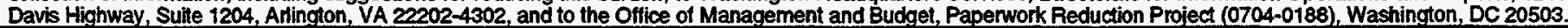
1. AGENCY USE ONLY
2. REPORT DATE
3. REPORT TYPE AND DATES COVERED
(Leave blank)
July 1996
Subcontract Report

\section{TITLE AND SUBTITLE}

A Technology Transfer Tracking System for NREL: Overview and Results

5. FUNDING NUMBERS

(C)

(TA) 2800.1000

6. AUTHOR(S)

Richard L. Chapman, Ph.D.

Marilyn J. Chapman, M.S.

7. PERFORMING ORGANIZATION NAME(S) AND ADDRESS(ES)

Chapman Research Group, Inc.

8. PERFORMING ORGANIZATION

6129 South Elizabeth Way

Littleton, Colorado 80121

9. SPONSORING/MONITORING AGENCY NAME(S) AND ADDRESS(ES)

National Renewable Energy Laboratory

1617 Cole Boulevard

Golden, CO $80401-3393$

REPORT NUMBER

10. SPONSORINGMONITORING AGENCY REPORT NUMBER

NRELTP-280-20880

DE96007947

\section{SUPPLEMENTARY NOTES}

NREL Technical Monitor: Helena Harman

\section{2a. DISTRIBUTION/AVAILABILITY STATEMENT}

National Technical Information Service

U.S. Department of Commerce

5285 Port Royal Road

Springfield, VA 22161 12b. DISTRIBUTION CODE

UC Category: 900

13. ABSTRACT (Maximum 200 words)

This report ia an overview of a five-part study that has explored a means for tracking the benefits of NREL research, developed a system based upon the perceptions of users of that research, and concluded with a full-scale survey of such users. The study demonstrates that NREL researchers strongly support the function of technology transfer leading to successful commercialization of NREL technology.

14. SUBJECT TERMS

technology transfer; benefits-tracking
15. NUMBER OF PAGES

16. PRICE CODE
19. SECURITY CLASSIFICATION OF ABSTRACT
20. LIMITATION OF ABSTRACT

UL 
